Int. J. Dev. Biol. 61: 733-747 (2017)

doi: $10.1387 / \mathrm{ijdb} .170227 \mathrm{~ms}$

\title{
CYP26 function is required for the tissue-specific modulation of retinoic acid signaling during amphioxus development
}

\author{
JOÃO E. CARVALHO\#, FRANÇOIS LAHAYE\#, JENIFER C. CROCE and MICHAEL SCHUBERT* \\ Sorbonne Universités, UPMC Université Paris 06, CNRS, Laboratoire de Biologie du Développement de \\ Villefranche-sur-Mer, Observatoire Océanologique de Villefranche-sur-Mer, Villefranche-sur-Mer, France
}

\begin{abstract}
During development, morphogens, such as retinoic acid (RA), act as mediators of intercellular communication systems to control patterning and cell fate specification processes. In vertebrates, the tightly regulated production and degradation of RA creates an anterior-posterior (A-P) morphogen gradient that is required for regional patterning of the embryo. RA catabolism in particular, mediated by members of the cytochrome P450 subfamily 26 (CYP26), has been highlighted as a key regulatory component for the formation of this gradient. RA-dependent developmental patterning is now widely recognized as a shared feature of all chordate groups (i.e. of vertebrates, tunicates, and cephalochordates). However, the evolutionary origin of the RA morphogen gradient still remains elusive. Thus, in the present study, we used pharmacological approaches to assess the roles of CYP26 enzymes in tissue-specific patterning processes in embryos and larvae of the cephalochordate amphioxus (Branchiostoma lanceolatum). Marker gene analyses revealed selective requirements for CYP26 activity in anterior endoderm, general ectoderm as well as central nervous system (CNS), but not in mesoderm. Furthermore, comparisons of the effects induced by CYP26 inhibition with those obtained by the pharmacological upregulation or downregulation of global RA signaling levels yielded evidence for a role of CYP26 in establishing an A-P RA gradient in the amphioxus embryo, important at least for patterning the CNS. Altogether, this work hence highlights the involvement of CYP26 in tissue-specific modulations of RA signaling activity in the amphioxus embryo and suggests that a RA morphogen gradient already functioned in the last common ancestor of all chordates.
\end{abstract}

KEY WORDS: Branchiostoma lanceolatum, cephalochordate, chordate evolution, morphogen gradient, retinoic acid

\section{Introduction}

In vertebrates, normal embryonic development requires a very tightly controlled balance of the total amount of available retinoic acid (RA), a vitamin A-derived morphogen. This balance is maintained through RA production by RALDH (retinaldehyde dehydrogenase) and RA degradation by CYP26 (cytochrome P450 subfamily 26) enzymes (Carvalho and Schubert, 2013; Dobbs-McAuliffe et al., 2004; Rydeen et al., 2015). In a target cell, the biological response to endogenous RA is mediated by heterodimers of two nuclear receptors, the retinoic acid receptor (RAR) and the retinoid $X$ receptor $(R X R)$, with the expression levels of RAR in particular being tightly linked to the availability of endogenous RA (Blomhoff and Blomhoff, 2006; Campo-Paysaa et al., 2008; Carvalho and Schubert, 2013).
CYP26 enzymes oxidize RAinto biologically inactive compounds and thus play critical roles in developmental patterning as well as in the compensation of endogenous RA level fluctuations (Sakai et al., 2001; White and Schilling, 2008). In both mice and zebrafish, for example, CYP26-deficient embryos are thus characterized by a mispatterning of the anterior central nervous system (CNS), the posterior trunk mesoderm, the tail, and the limbs as well as by an increased sensitivity to RA teratogenicity (Hernandez et al., 2007; Rydeen and Waxman, 2014; White and Schilling, 2008).

\footnotetext{
Abbreviations used in this paper: A-P, anterior-posterior; BMS, Bristol-Myers Squibb; CNS, central nervous system; CV, cerebral vesicle; DIC, differential interference contrast; DMSO, dimethyl sulfoxide; ESN, ectodermal sensory neurons; Hpf, hours post fertilization; PPS, primary pigment spot; R115866, Talarozole; RA, retinoic acid.
}

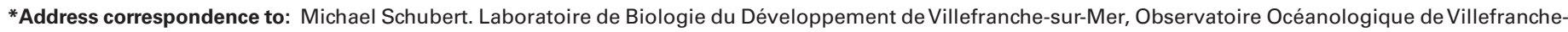

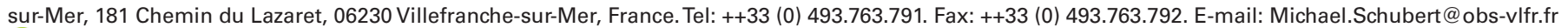
(iD) http://orcid.org/0000-0002-2341-712X - \#Note: Equal contributions.
} 
The majority of these phenotypes can be explained by the requirement of CYP26 enzymes for the creation of RA gradients along the anterior-posterior (A-P) axis of the embryo. These gradients are characterized by high RA levels at the head-trunk boundary, a territory marked by conspicuous mesodermal RALDH expression, and decline both anteriorly and posteriorly (Rydeen et al., 2015; Schilling et al., 2016; Shimozono et al., 2013; White et al., 2007). Although the establishment of these morphogen gradients generally depends on intricate feedback mechanisms within the RA signaling cascade, CYP26 enzyme function both anteriorly and posteriorly in the embryo is critically required for initiation and maintenance of these gradients (Schilling et al., 2016).

Here, we investigate the tissue-specific roles of RA degradation during development of the cephalochordate amphioxus (Branchiostoma lanceolatum) in an effort to obtain insights into the evolution of RAgradients in chordates. Amphioxus possesses three CYP26 genes (CYP26-1, CYP26-2, and CYP26-3), which originated by lineage-specific duplication and form a single cluster in the genome (Albalat and Cañestro, 2009; Carvalho et al., 2017). As in vertebrates, the amphioxus CYP26 enzymes assume two main functions during development that have been sub-functionalized, with CYP26-2 mediating RA-dependent developmental patterning and CYP26-1 and CYP26-3 assuming the protection of the embryo against RA teratogenicity (Carvalho et al., 2017). However, details about the tissue-specific actions of CYP26 during amphioxus development as well as data supporting or refuting the existence of a RA gradient in the amphioxus embryo still remain elusive.

We thus used pharmacological inhibition of CYP26 enzyme function to characterize the roles of CYP26 in tissue-specific patterning processes during amphioxus development. Furthermore, we compared and contrasted the effects of CYP26 inhibition with those obtained by treatments with RA or a RAR antagonist, hence allowing an estimate of the importance of RA degradation in the global regulation of the developmental RA signaling system. Tissuespecific phenotypes in endoderm, mesoderm, ectoderm, and CNS were analyzed by assaying expression of six tissue-specific marker genes, En (Engrailed), Pax2/5/8 (Paired box 2/5/8), Pitx (Pairedlike homeodomain), Pax6 (Paired box 6), TIx (T-cell leukemia homeobox), and Prdm12 (PR/SET domain 12) (Beaster-Jones et al., 2008; Boorman and Shimeld, 2002; Glardon et al., 1998; Holland et al., 1997; Holland and Holland, 1998; Kaltenbach et al., 2009; Kozmik et al., 1999; Lu et al., 2012; Schubert et al., 2005; Schubert et al., 2006; Somorjai et al., 2008; Soukup et al., 2015; Thélie et al., 2015; Yasui et al., 2000; Zieger et al., 2016). Altogether, this work establishes that CYP26 function is a crucial component of the overall developmental RA signaling system, modulating RAactivity in very specific domains of the embryo: the anterior endoderm, the anterior- and posterior-most ectoderm, and along the A-P axis of the CNS, but not in the mesoderm. The results are further consistent with a role for CYP26 enzymes in establishing a RA morphogen gradient along the A-P axis of the amphioxus embryo that is required for patterning, at least, the developing CNS. This finding suggests that the last common ancestor of all chordates already possessed an intricate and tightly regulated RA signaling system capable of creating an efficientA-PRAmorphogen gradient required for the regionalization of the CNS.

\section{Results}

\section{CYP26-2 expression as a proxy for endogenous retinoic acid degradation in developing amphioxus}

The expression of the three amphioxus CYP26 genes (CYP261, CYP26-2, and CYP26-3) has previously been described in $B$. lanceolatum embryos and larvae (Carvalho et al., 2017). It has thus been shown that transcription of CYP26-1 and CYP26-3 is extremely low during development, while that of $C Y P 26-2$ is highly conspicuous and tissue-specific (Carvalho et al., 2017). In addition, alterations of RA signaling levels affect CYP26-1 and CYP26-3 expression much more strongly than that of CYP26-2 (Carvalho et al., 2017). For these reasons, we concluded that CYP26-1 and CYP26-3 likely assume the protection of the embryo from fluctuating RA levels, while CYP26-2 mediates RA-dependent developmental patterning (Carvalho et al., 2017). We hence decided to assay the expression of CYP26-2 to characterize patterning-related RA degradation activity in developing amphioxus embryos and larvae.

As previously described (Carvalho et al., 2017), at $18 \mathrm{hpf}$ (hours post fertilization), CYP26-2 is expressed in the rostral ectoderm and anterior endoderm, in the two anterior-most somites, in the cerebral vesicle (CV) of the CNS as well as in the posterior region, in a domain corresponding to the tail bud (Fig. 1 A-A"). Later, at 21 and $24 \mathrm{hpf}$, inconspicuous expression of CYP26-2 is further found in the posterior-most ectoderm overlying the tail bud as well as in individual ectodermal cells along the flanks of the embryo (Fig. 1 B-C"). At these stages, an additional CYP26-2 domain appears in the ventral region of the forming pharynx that is maintained through subsequent development (Fig. 1 B-D"). Finally, in early larvae, at $36 \mathrm{hpf}$, the gene is no longer detectable in the anterior-most ectoderm, but it is still expressed in all the other domains (Fig. 1 E-E").

Treatment with the CYP26 inhibitor R115866 generally leads to an expansion of CYP26-2 expression during development. At 18 $\mathrm{hpf}$, for instance, the domain in the posterior tip of the embryo is enlarged (Fig. 1 F-F"), and, by 21 and $24 \mathrm{hpf}$, the CYP26-2 domains in the anterior ectoderm and endoderm as well as in the CNS are expanded posteriorly (Fig. 1 G-H"). This upregulation of CYP26-2 in anterior and posterior tissues becomes even more conspicuous at $30 \mathrm{hpf}$ (Fig. 1 I-I'), and, by $36 \mathrm{hpf}$, the signal has spread throughout most of the early larva, most noticeably in general ectoderm and CNS (Fig. $1 \mathrm{~J}-\mathrm{J}$ "). Treatments with exogenous RA generally induce a similar expansion of CYP26-2 expression in the amphioxus embryo (Fig. 1 K-O"). However, compared to the CYP26 inhibitor, RA elicits a stronger response at 18 and 21 hpf (Fig. 1 F-G",K-L"), a similar one at 24 and $30 \mathrm{hpf}$ (Fig. $1 \mathrm{H}-\mathrm{I}$ ", M-N"), and a weaker one

Fig. 1 (opposite). Developmental expression of Branchiostoma lanceolatum CYP26-2. (A-E") DMSO controls. (F-J") CYP26 inhibitor (R115866) treatments (final concentration: $0.5 \mu \mathrm{M})$. (K-O") all-trans retinoic acid (RA) treatments (final concentration: $0.1 \mu M)$. (P-T") RAR antagonist (BMS493)

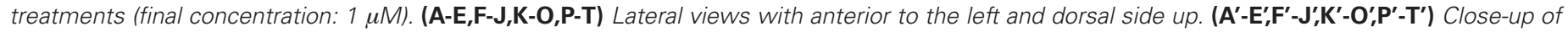
regions of interest highlighted by dashed boxes in the lateral views. (A"-E",'F"-J",K"-O",P"-T") Dorsal views with anterior to the left. Developmental stages are given as hours post fertilization (hpf) at $19^{\circ} \mathrm{C}$. For controls, tissues expressing the gene are marked as described in the legend. For treatment conditions, marked areas highlight expression changes (see main text for details). Black arrows indicate loss of CYP26-2 expression. Scale bar in (A) is

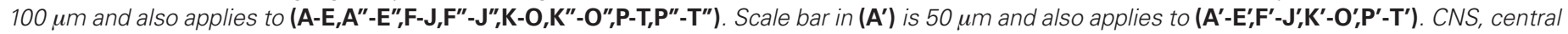
nervous system; $C V$, cerebral vesicle; PPS, primary pigment spot. 


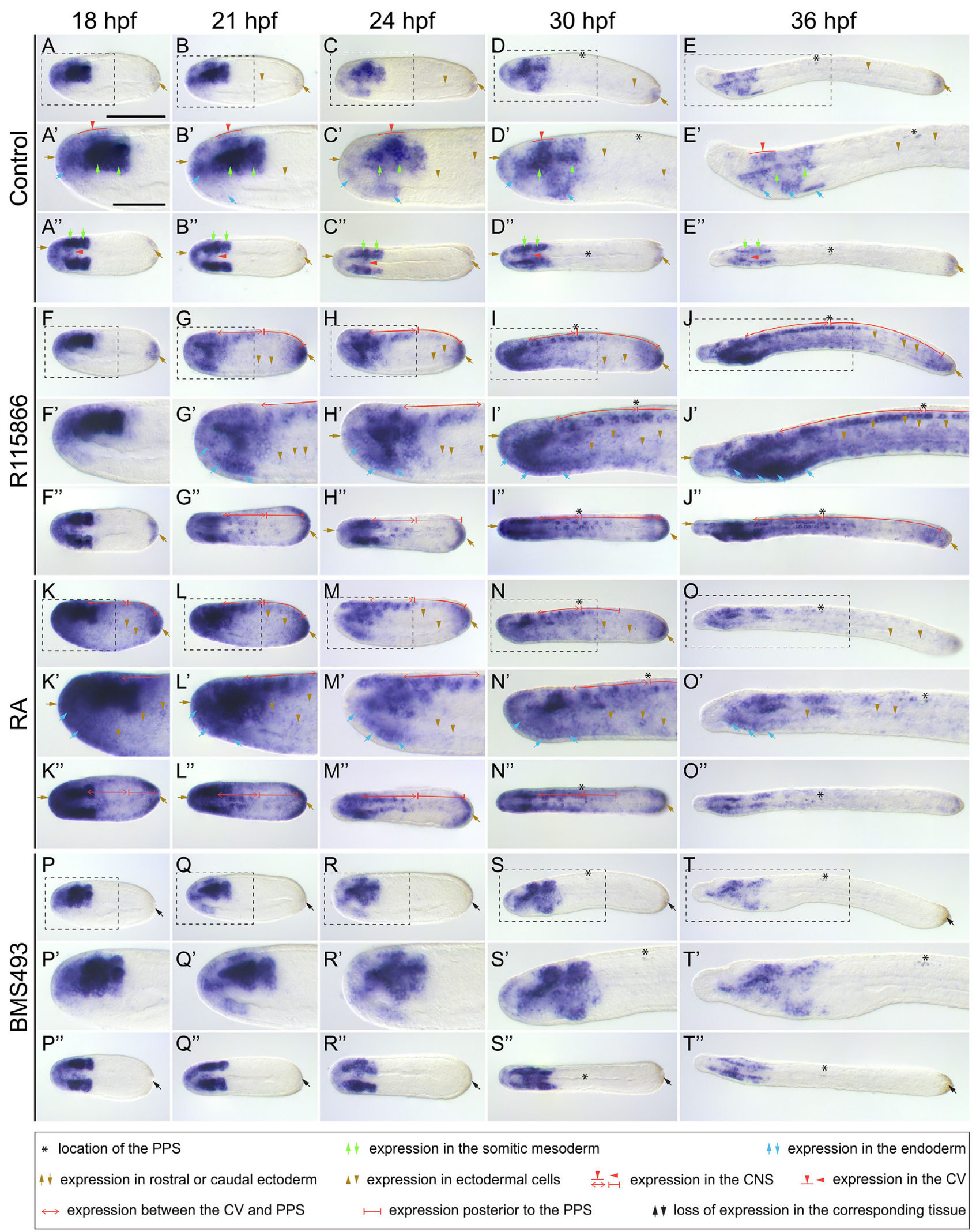


at the 36 hpf (Fig. 1 J-J",O-O'). Thus, at 18 and 21 hpf, conspicuous CYP26-2 staining is observed anteriorly and posteriorly as well as along almost the entire A-P axis of the general ectoderm (Fig. $1 \mathrm{~K}-\mathrm{L}$ "), while at $36 \mathrm{hpf}$, expression of the gene appears only slightly upregulated in the anterior regions of the larva and along the CNS (Fig. 1 O-O"). In contrast, treatment with the RAR antagonist BMS493 induces no noticeable changes of CYP26-2 expression anteriorly, but abolishes the posterior signal (Fig. 1 P-T").

Altogether, these results show that CYP26-2 is expressed in anterior mesoderm and endoderm, the general ectoderm and CNS, most prominently in anterior and posterior territories of developing amphioxus embryos and larvae. Furthermore, the pharmacological treatments along with previous morphological studies (Carvalho et al., 2017) suggest that CYP26 function is required for the tissue- specific regulation of RA signaling activity during amphioxus development. To further characterize the involvement of CYP26 enzymes in RA-dependent patterning processes, we next analyzed expression of a series of tissue-specific marker genes in amphioxus embryos and larvae following pharmacological treatments.

\section{CYP26 action is not involved in patterning the anterior am- phioxus mesoderm}

Because CYP26 is conspicuously expressed in the mesoderm, we first characterized the potential action of CYP26 in this tissue. We thus assessed the expression of two mesodermal markers, En and Pax2/5/8, in embryos and larvae treated with R115866 and compared the results to embryos and larvae treated with RA or BMS493. It should be noted that expression profiles of En and

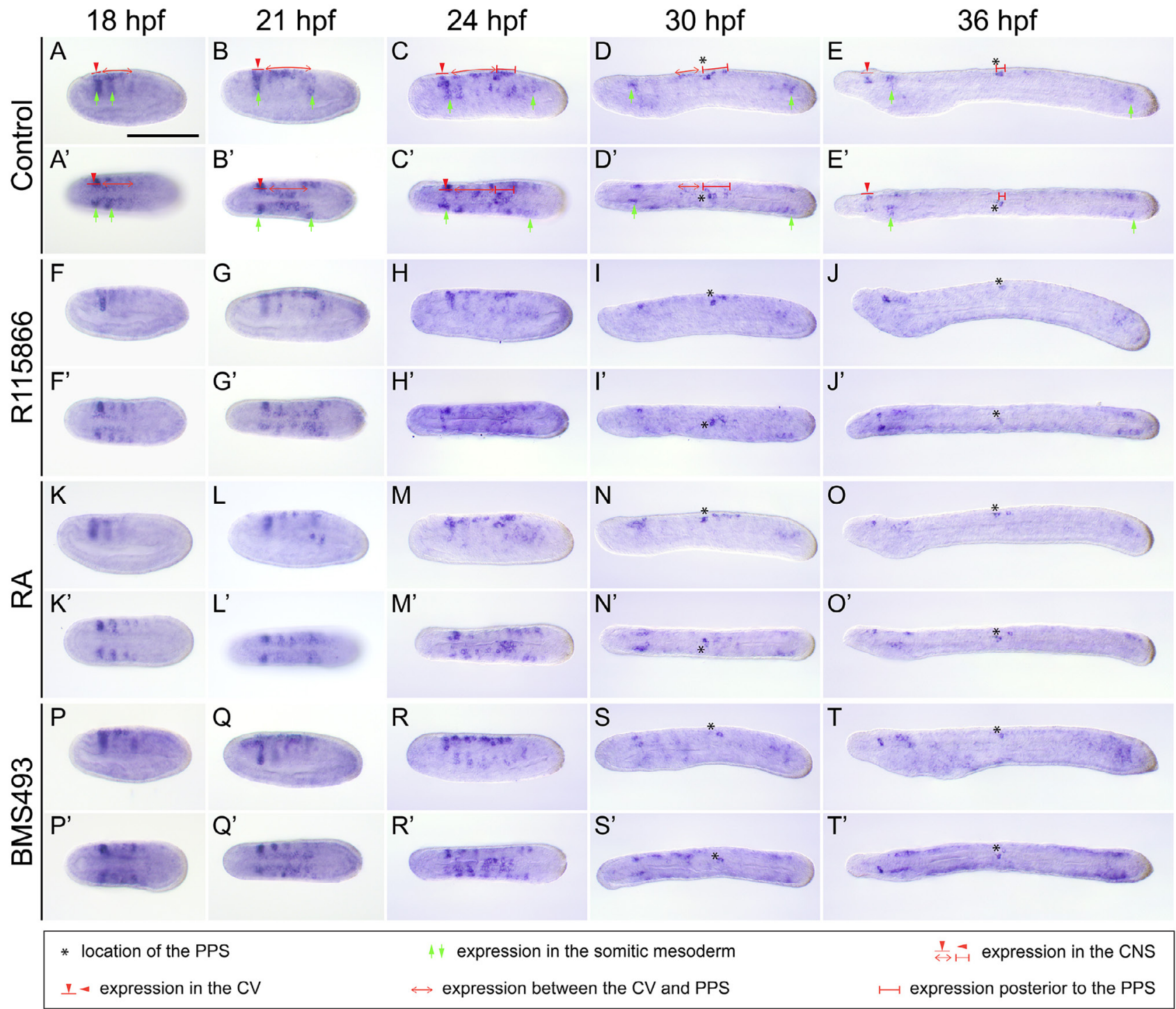

Fig. 2. Developmental expression of Branchiostoma lanceolatum Engrailed(En). (A-E') DMSO controls. (F-J') CYP26 inhibitor (R115866) treatments (final concentration: $0.5 \mu \mathrm{M})$. (K-O') all-trans retinoic acid (RA) treatments (final concentration: $0.1 \mu M)$ ). (P-T") RAR antagonist (BMS493) treatments

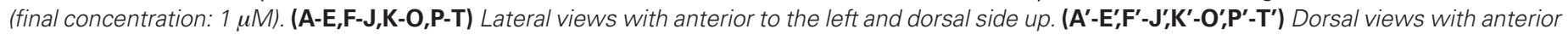
to the left. Developmental stages are given as hours post fertilization (hpf) at $19^{\circ} \mathrm{C}$. For controls, tissues expressing the gene are marked as described in the legend. For treatment conditions, marked areas highlight expression changes (see main text for details). Scale bar in (A) is 100 um and is applicable to all specimens. CNS, central nervous system; CV, cerebral vesicle; PPS, primary pigment spot. 


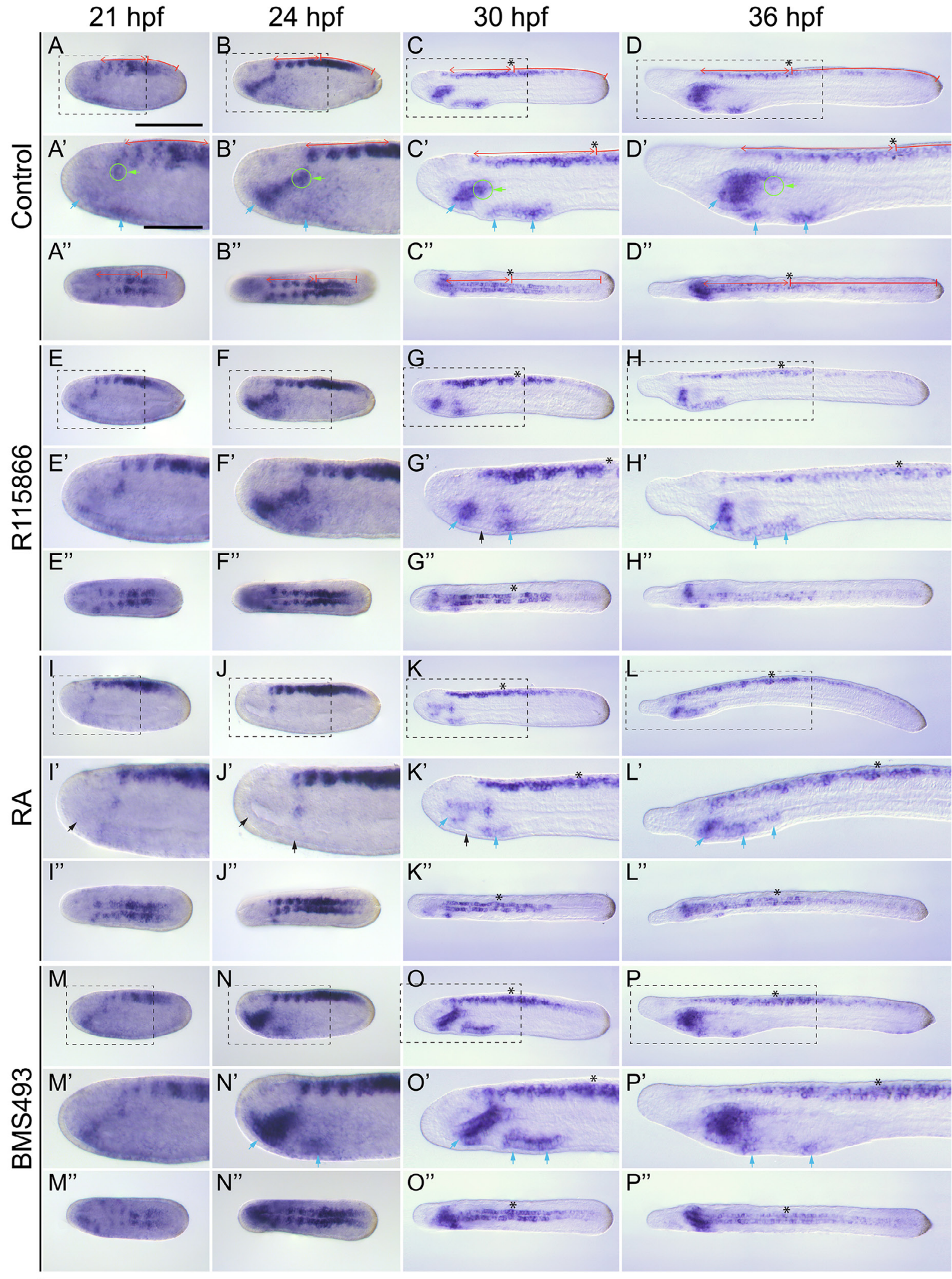

* location of the PPS

$\leftrightarrow \mapsto$ expression in the CNS
Ay expression in the mesoderm

$\leftrightarrow$ expression between the $\mathrm{CV}$ and PPS

it loss of expression in the corresponding tissue
Fig. 3. Developmental expression of Branchiostoma lanceolatum Pax2/5/8. (A-D") DMSO controls. (E-H") CYP26 inhibitor (R115866) treatments (final concentration: $0.5 \mu \mathrm{M})$. (I-L") all-trans retinoic acid (RA) treatments (final concentration: 0.1 uM). (M-P") RAR antagonist (BMS493) treatments (final concentration: $1 \mu \mathrm{M}$ ). (AD,E-H,I-L,M-P) Lateral views with anterior to the left and dorsal side up. (A'-D', E'-H','I'-L','M'$\left.\mathbf{P}^{\prime}\right)$ Close-up of regions of interest highlighted by dashed boxes in the lateral views. (A"D",E"--H",I"-L",M"--P") Dorsal views with anterior to the left. Developmentalstages are given as hours post fertilization (hpf) at $19^{\circ} \mathrm{C}$. For controls, tissues expressing the gene are markedas described in the legend. For treatment conditions, marked areas highlight expression changes (see main text for details). Black arrows indicate loss of Pax2/5/8 expression. Specifically, blue arrows allow an assessment of the relative distances between distinct endodermal expression domains. Scale bar in (A) is 100 um and also applies to (A-D,A"-D",E-H,E"H",I-L,I"-L",M-P,M"$\left.\mathbf{P}^{\prime \prime}\right)$. Scale bar in $\left(\mathbf{A}^{\prime}\right)$ is $50 \mu \mathrm{m}$ and also applies to (A'-D', $\mathbf{E}^{\prime}-\mathbf{H}^{\prime}, \mathbf{I}^{\prime}$ $\left.\mathbf{L}^{\prime}, \mathbf{M}^{\prime}-\mathbf{P}^{\prime}\right)$. CNS, central nervous system; $C V$, cerebral vesicle; PPS, primary pigment spot. 


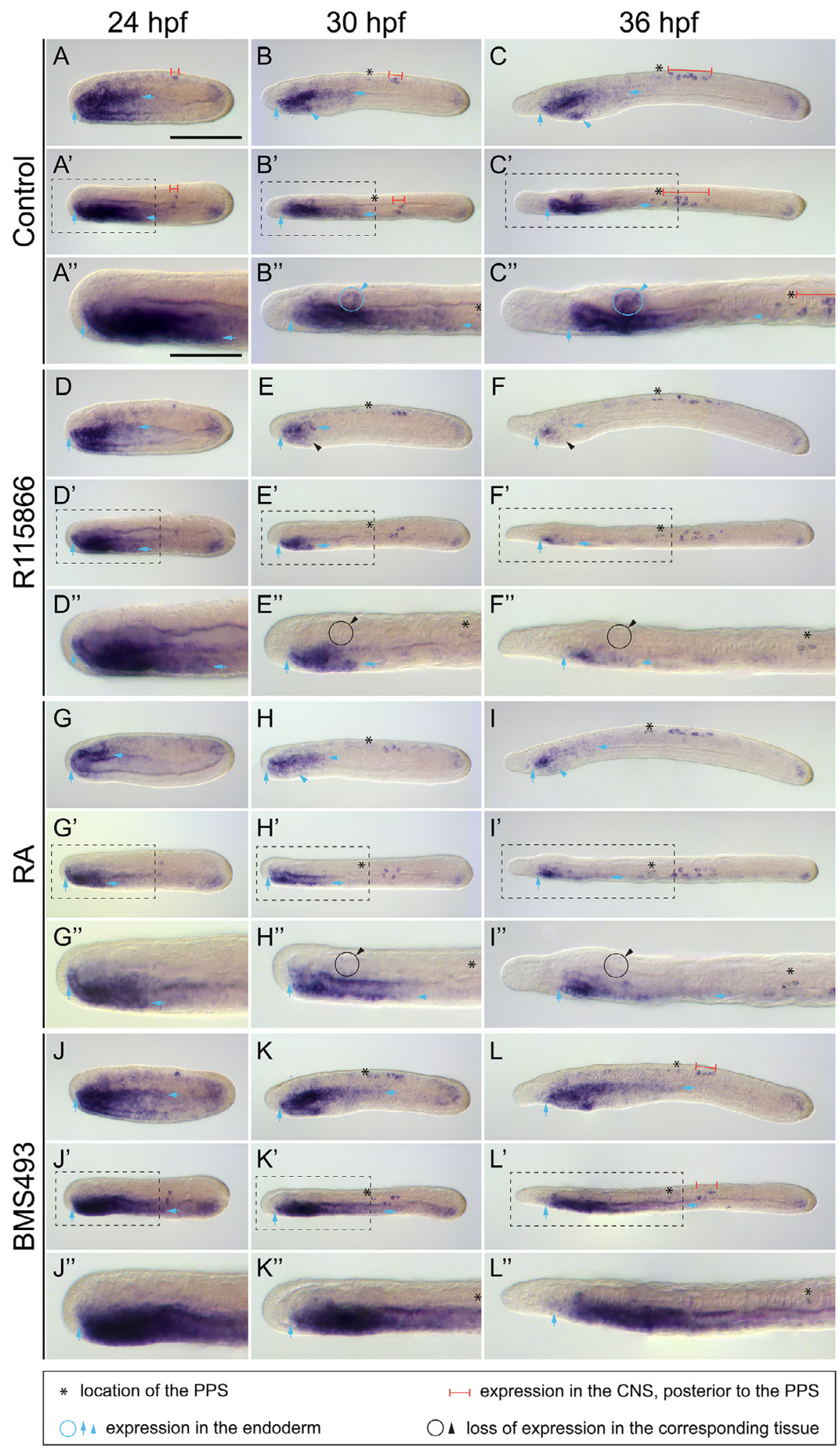

Pax2/5/8 during amphioxus development have previously been described in the Florida amphioxus, $B$. floridae (Beaster-Jones et al., 2008; Holland et al., 1997; Holland and Holland, 1998; Kozmik et al., 1999), establishing that they are indeed expressed in mesodermal structures. Moreover, Pax2/5/8expression has also been characterized in the amphioxus species used in this study, $B$. lanceolatum (Somorjai et al., 2008), and, following treatments with R115866, RA or the RAR antagonist BMS009, in developing $B$. floridae, albeit only at specific developmental stages (Koop et al., 2014; Schubert et al., 2006).

During $B$. lanceolatum development, the early mesodermal expression of En, from 18 through $24 \mathrm{hpf}$, is restricted to the posterior wall of the newly-formed somites, forming a striped pattern that progresses posteriorly with the elongation of the embryo (Fig. 2 A-C'). At 21 and $24 \mathrm{hpf}$, En expression in the anteriorand posterior-most somite pairs is conspicuous, while the En signal in the intermediate somite pairs is much less widespread (Fig. 2 B-C'). At 30 and 36 hpf, contrary to what has previously been described for the Florida amphioxus (Holland et al., 1997), we were able to identify Enexpression in newly-formed somites derived from the tail bud (Fig. 2D-E'). Regarding Pax2/5/8, in contrast to En, its mesodermal expression during $B$. lanceolatum development is detectable starting at about 21 $\mathrm{hpf}$ in a thickening of the mesothelial wall of the anterior-most somite on the left side (Fig. 3 A-A"). During subsequent development, this mesodermal Pax2/5/8 signal, which corresponds to Hatschek's nephridium, expands slightly until $36 \mathrm{hpf}$ (Fig. 3 B-D"). Intriguingly, despite the conspicuous expression of CYP262 in anterior mesoderm, treatments with R115866 or RAdo neither affect the expression of $E n$ in the somitic mesoderm (Fig. 2 F-O'), nor the mesodermal expression of Pax2/5/8 (Fig. 3 E-L"). Similarly, BMS493 does not induce any marked changes in the mesodermal

Fig. 4. Developmental expression of Branchiostoma lanceolatum Pitx. (A-C") DMSO controls. (D-F") CYP26 inhibitor (R115866) treatments (final concentration: $0.5 \mu \mathrm{M})$. (G-I") all-trans retinoic acid (RA) treatments (final concentration: $0.1 \mu \mathrm{M}$ ). (J-L") RAR antagonist (BMS493) treatments (final concentration: $1 \mu \mathrm{M})$. (A-C,D-F,G-I,J-L) Lateral views with anterior to the left and dorsal side up.

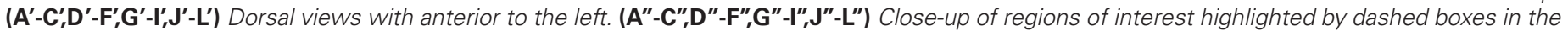
dorsal views. Developmental stages are given as hours post fertilization (hpf) at $19^{\circ} \mathrm{C}$. For controls, tissues expressing the gene are marked as described in the legend. For treatment conditions, marked areas highlight expression changes (see main text for details). Black circles and arrowheads indicate loss of Pitx expression. Specifically, for each specimen, blue arrows show the anterior (vertical arrow on the left) to posterior (horizontal arrow on the

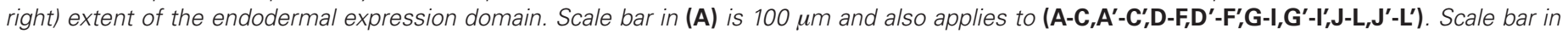
(A") is $50 \mu \mathrm{m}$ and also applies to (A"-C",':"-F",G"-I",'J"-L"). CNS, central nervous system; PPS, primary pigment spot. 


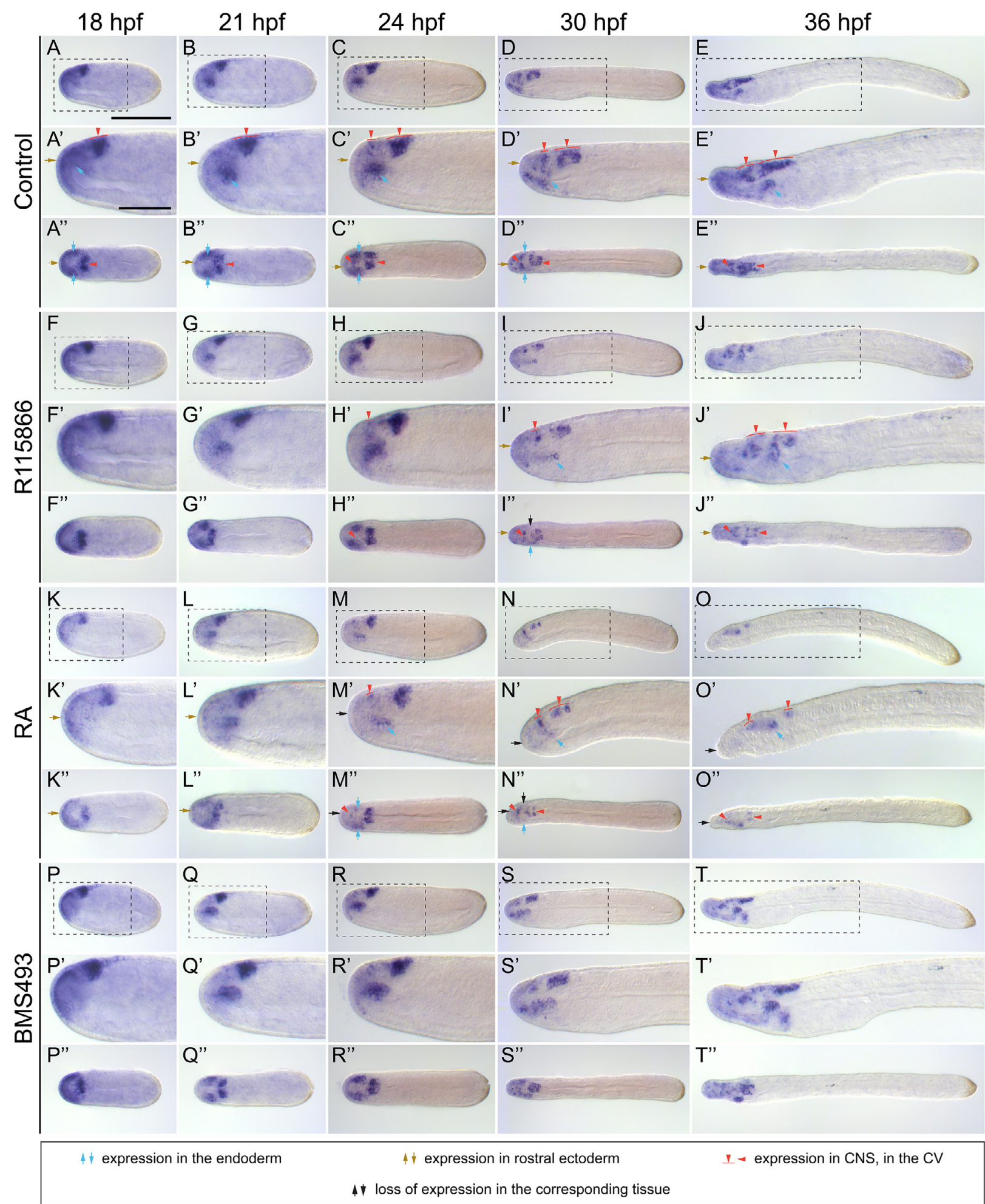

Fig. 5. Developmental expression of Branchiostoma lanceolatum Pax6. (A-E") DMSO controls. (F-J") CYP26 inhibitor (R115866) treatments (final concentration: $0.5 \mu \mathrm{M})$. (K-O") all-trans retinoic acid (RA) treatments (final concentration: $0.1 \mu \mathrm{M})$. (P-T") RAR antagonist (BMS493) treatments (final concentration: $1 \mu \mathrm{M})$. (A-E,F-J,K-O,P-T) Lateral views with anterior to the left and dorsal side up. $\left(\mathbf{A}^{\prime}-\mathbf{E}^{\prime}, \mathbf{F}^{\prime}-\mathbf{J}^{\prime}, \mathbf{K}^{\prime}-\mathbf{O}^{\prime}, \mathbf{P}^{\prime}-\mathbf{T}^{\prime}\right)$ Close-up of regions of interest highlighted by dashed boxes in the lateral views. (A"-E",F"-J",'K"-O','P"-T") Dorsal views with anterior to the left. Developmental stages are given as hours post fertilization (hpf) at $19^{\circ} \mathrm{C}$. For controls, tissues expressing the gene are marked as described in the legend. For treatment conditions, marked areas highlight expression changes (see main text for details). Black arrows indicate loss of Pax6 expression. Scale bar in (A) is $100 \mu$ m and

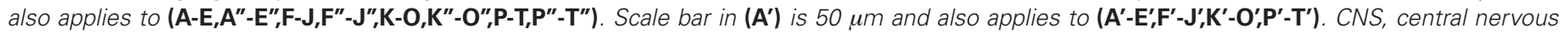
system; CV, cerebral vesicle. 
expression of En (Fig. 2 P-T') and Pax2/5/8 (Fig. 3 M-P”).

These results thus suggest that RA degradation mediated by CYP26 is not overtly involved in the developmental patterning of the mesoderm. This finding is consistent with previous reports assessing the functions of RA signaling in developing amphioxus (Bertrand et al., 2015; Carvalho et al., 2017; Koop et al., 2014; Schubert et al., 2005).

\section{CYP26 is a key factor in the establishment of anterior endo- dermal structures in amphioxus}

In previous reports, it has been suggested that CYP26 action is required for patterning the anterior amphioxus endoderm, with the inhibition of CYP26 activity leading to the loss of mouth, gill slits, endostyle, and club-shaped gland (Carvalho et al., 2017; Koop et al., 2014). To complement these results, we characterized the impact of treatments with CYP26 inhibitor, RA or RAR antagonist on the endodermal expression of Pax2/5/8, Pitx, and Pax6 in B. lanceolatum embryos and larvae. The developmental expression of all three genes has previously been established in B. floridae (Boorman and Shimeld, 2002; Glardon et al., 1998; Kozmik et al., 1999; Soukup et al., 2015), those of Pax2/5/8 and Pitx have also been reported in B. lanceolatum (Somorjai et al., 2008; Soukup et al., 2015), and that of Pitx also in B. japonicum (Yasui et al., 2000). Moreover, effects of R115866, RA, and the RAR antagonist BMS009 have been assessed for Pax2/5/8 and Pitx in B. floridae, but exclusively in mid-neurulae and early larvae (Koop et al., 2014; Schubert et al., 2005; Schubert et al., 2006).

In the endoderm, expression of $B$. lanceolatum Pax2/5/8 is first detectable anteriorly at $21 \mathrm{hpf}$ (Fig. 3 A-A"). Subsequently, at $24 \mathrm{hpf}$, Pax2/5/8 expression in the anterior endoderm becomes subdivided into three individual domains: the first one, localized anteriorly, is in a territory giving rise to Hatschek's left and right diverticula, the second one is located slightly posteriorly, where the mouth will penetrate, and the third one is in the ventral endoderm on the left side of the forming pharynx where the gill slits will form (Fig. 3 B-B'). At 30 and 36 hpf, Pax2/5/8 expression in the amphioxus pharyngeal endodermal is detectable in different structures: on the left side, transiently in Hatschek's left diverticulum and where the mouth will open, on the right side, in the endostyle, and, ventrally, where the gill slits will penetrate (Fig. 3 C-D"). Concerning Pitx, at 24 hpf, this gene is expressed exclusively on the left side in the anterior half of the endoderm (Fig. 4 A-A"). During subsequent development, at 30 and 36 hpf, expression of Pitx becomes restricted to the left side of the pharyngeal endoderm and to the developing club-shaped gland, on both the left and the right side of the body (Fig. 4 B-C"). This bilateral signal of Pitx in the $B$. lanceolatum club-shaped gland contrasts with previous reports in $B$. japonicum, where the clubshaped gland-associated expression of the gene seems to be limited to the left side (Yasui et al., 2000). Finally, for Pax6, the first endodermal expression of this gene is observable at $18 \mathrm{hpf}$, in anterior cells located dorsolaterally on either side of the endoderm, marking the presumptive territories of Hatschek's left and right diverticula (Fig. 5 A-A"). During subsequent development, Pax6 remains detectable in both of these endodermal pouches without extending to any other endodermal structure (Fig. 5 B-D"). By 36 hpf, Pax6 expression is only observable in Hatschek's left diverticulum (Fig. 5 E-E").

Treatment with R115866 affects the expression of all three marker genes, although in different ways. Thus, Pax2/5/8 expression seems largely unaffected by the treatment at 21 and $24 \mathrm{hpf}$ (Fig. 3 E-F"), whereas, by 30 and 36 hpf, expression in all three pharyngeal Pax2/5/8 domains is less conspicuous (Fig. 3 G-H'). R115866 also restricts endodermal Pitx expression along the A-P axis starting at $24 \mathrm{hpf}$ in a posterior to anterior progression (Fig. 4 $D-F$ "). Expression in the club-shaped gland is also completely lost following CYP26 inhibition (Fig. 4 E-F"), with only the Pitx signal in Hatschek's left diverticulum still being discernable in the endoderm at 36 hpf (Fig. 4 F-F'). In contrast, treatment with R115866 does not affect endodermal Pax6 expression until 30 hpf (Fig. 5 $\left.\mathrm{F}-\mathrm{H}^{\prime \prime}\right)$, when the signal is no longer observable in Hatschek's right diverticulum and is downregulated in Hatschek's left diverticulum, albeit not completely (Fig. 5 I-J"). Exogenous RA treatments also reduce the endodermal expression domains of Pax2/5/8 (Fig. 3 I-L"), Pitx (Fig. 4 G-I"), and Pax6 (Fig. 5 K-O"). However, in contrast to R115866 treatments, RA affects Pax2/5/8 expression already at $21 \mathrm{hpf}$, leading to a loss of most of the endodermal expression (Fig. 3 E-E',I-I'). Furthermore, the domain of Pitx is more severely restricted to anterior endodermal territories by RA at 24 hpf (Fig. 4 D-D",G-G"), although, at 30 and $36 \mathrm{hpf}$, this effect is more pronounced following CYP26 inhibition (Fig. 4 EF",H-I"). Likewise, the endodermal Pax6 domain is already less conspicuous at $24 \mathrm{hpf}$ following RA treatment (Fig. $5 \mathrm{H}-\mathrm{H}$ ", M-M"). Consistent with the R115866 and RA results, BMS493 treatments induce a posterior expansion of the endodermal Pax2/5/8 (Fig. 3 M-P') and Pitx (Fig. 4 J-L') domains, particularly at early developmental stages, but do not induce any significant changes in the endodermal expression of Pax6 (Fig. 5 P-T').

Altogether, these results thus support previous findings (Carvalho et al., 2017; Koop et al., 2014) suggesting that CYP26 is required for both regional patterning of the endoderm and the development of specific pharyngeal structures.

\section{CYP26 plays a major role in patterning specific ectodermal sensory neuron populations}

Given the role of RA signaling in patterning the amphioxus general ectoderm (Schubert et al., 2004) and the scattered expression of CYP26-2 in this tissue (Carvalho et al., 2017), we next assessed the effects of CYP26 inhibition in the general ectoderm by assessing expression of Pax6, TIx as well as Prdm12. The expression profiles of Pax6 and TIx have previously been described during B. floridae development (Glardon et al., 1998; Kaltenbach et al., 2009; Lu et al., 2012) and those of TIx have been reported in developing $B$. lanceolatum (Zieger, 2016). Furthermore, the effects of RA and BMS493 on T/x expression have been assessed in B. lanceolatum (Zieger, 2016).

Ectodermal expression of Pax6 is detectable at $18 \mathrm{hpf}$ in the most anterior region of the ectoderm, where it persists until early larval stages (Fig. 5 A-E"). TIx expression in the ectoderm commences at $18 \mathrm{hpf}$ as a continuous domain in the ventral ectoderm and is further detectable in ectodermal sensory neuron (ESN) progenitors (Kaltenbach et al., 2009) emanating from this ventral domain and migrating dorsally (Fig. 6A,A"). This expression pattern is largely maintained at 21 and 24 hpf (Fig. 6 B,B",C,C"), although, by $24 \mathrm{hpf}$, the continuous ventral expression of $T / x$ is resolved into a spotty pattern marking individual ectodermal cells (Fig. 6 C,C"). By $30 \mathrm{hpf}, \mathrm{Tl} x$ is no longer detectable in the ventral ectoderm, but expression persists in ESN progenitors 


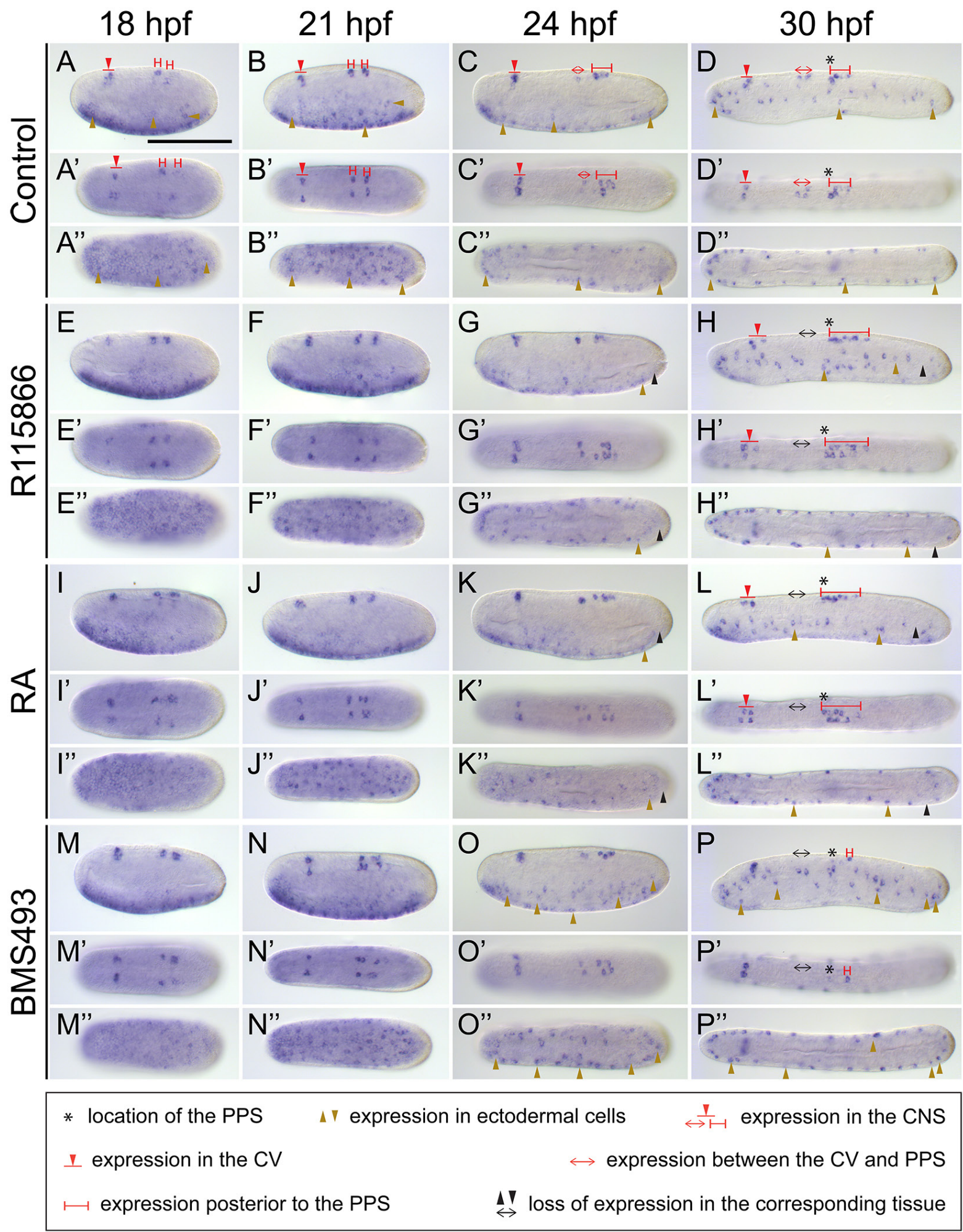

Fig. 6. Developmental expression of Branchiostoma lanceolatum TIx. (A-D") DMSO controls. (EH") CYP26 inhibitor (R115866) treatments (final concentration: $0.5 \mu \mathrm{M})$. (I-L") all-trans retinoic acid (RA) treatments (final concentration: $0.1 \mu \mathrm{M})$. (M-P") RAR antagonist (BMS493) treatments (final concentration: 1

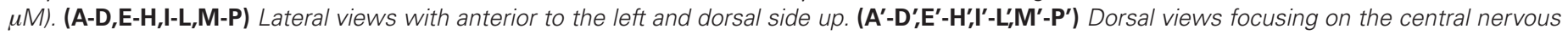
system with anterior to the left. (A"-D",E"-H",I"-L",'M"-P") Dorsal views focusing on the ventral ectodermal surface with anterior to the left. Developmental stages are given as hours post fertilization (hpf) at $19^{\circ} \mathrm{C}$. For controls, tissues expressing the gene are marked as described in the legend. For treatment conditions, marked areas highlight expression changes (see main text for details). Black double arrows and arrowheads indicate loss of Tlx expression. Scale bar in (A) is $100 \mu \mathrm{m}$ and is applicable to all specimens. CNS, central nervous system; CV, cerebral vesicle; PPS, primary pigment spot. 
dispersed along the lateral ectoderm (Fig. 6 D,D"). Similar to $T / x$, at 21 and $24 \mathrm{hpf}, \operatorname{Prdm} 12$ is expressed transiently and very inconspicuously in individual cells of the ventral ectoderm (Fig. 7 A,A',B,B'). In contrast, by $30 \mathrm{hpf}$, Prdm12 expression in the ectoderm is completely downregulated (Fig. 7 C-D').

Treatments with R115866 affect the ectodermal expression of both Pax6 and TIx. Thus, while R115866 does not affect early expression of Pax6 in the rostral ectoderm between 18 and 24 hpf (Fig. 5 F-H'), the signal is less conspicuous at 30 and 36 hpf (Fig. 5 I-J"). For the ectodermal expression of T/x, no effects of R115866 are discernable until 24 hpf (Fig. 6 E,E",F,F"). At this stage, the treatments seem to shift the distribution of T/x-positive ESN progenitors anteriorly (Fig. 6 G,G"), a trend that is somewhat more pronounced at $30 \mathrm{hpf}$ (Fig. $6 \mathrm{H}, \mathrm{H}$ "). In contrast to $T / x$, we were unable to document an effect of R115866 treatments on the Prdm12-expressing ESN progenitor population (Fig. 7

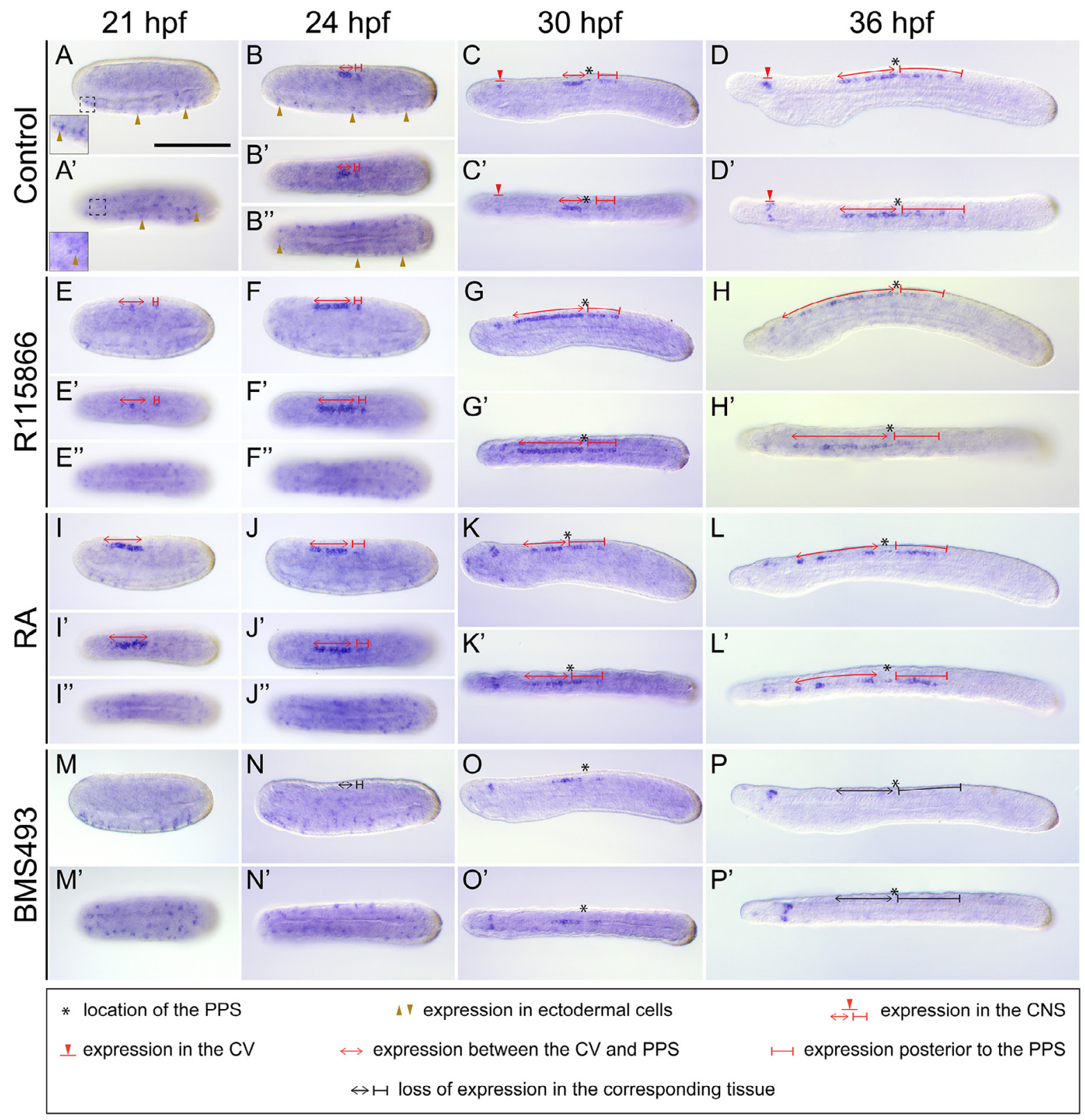

Fig. 7. Developmental expression of Branchiostoma lanceolatum Prdm 12. (A-D') DMSO controls. (E-H') CYP26 inhibitor (R115866) treatments (final concentration: $0.5 \mu \mathrm{M}$ ). (I-L') all-trans retinoic acid (RA) treatments (final concentration: $0.1 \mu \mathrm{M})$. (M-P') RAR antagonist (BMS493) treatments

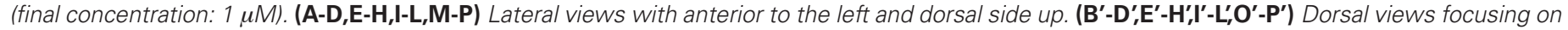

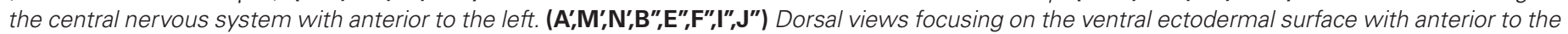
left. In A and A', shown as insets, are close-ups (2.25X) of the region of interest marked by the dashed boxes. Developmental stages are given as hours post fertilization (hpf) at $19^{\circ} \mathrm{C}$. For controls, tissues expressing the gene are marked as described in the legend. For treatment conditions, marked areas highlight expression changes (see main text for details). Black double arrows and black double blocked lines indicate loss of Prdm12 expression. Scale bar in (A) is $100 \mu \mathrm{m}$ and is applicable to all specimens. CNS, central nervous system; CV, cerebral vesicle; PPS, primary pigment spot. 
$\mathrm{E}, \mathrm{E}$ ', F,F"). Consistent with the results obtained with $\mathrm{R} 115866$, exogenous RA also affects the expression of both Pax6 and TIx in the ectoderm. However, RA weakens Pax6 expression in the anterior ectoderm already by $18 \mathrm{hpf}$ (Fig. $\left.5 \mathrm{~K}-\mathrm{K}^{\prime \prime}\right)$ and completely downregulates ectodermal Pax 6 expression by 24 hpf (Fig. 5 L-O"). RA treatments also affect the distribution of TIx-expressing ESN progenitors along the A-P axis at 24 and 30 hpf, shifting them towards more anterior levels of the ectoderm (Fig. 6 I,I',J,J',K,K',L,L'). For Prdm12, it was again difficult to assess the effects of the treatments (Fig. 7 I,I',J,J"). BMS493 treatments might somewhat weaken the rostral ectodermal expression of Pax6, although this effect is not consistently seen in all assayed stages (Fig. 5 P-T'). Conversely, the RAR antagonist might increase the overall number of T/x-expressing cells at 24 and 30 hpf (Fig. 6 O,O”,P,P”). For Prdm12, no unequivocal effect on its ectodermal expression was observed upon treatment with BMS493 (Fig. 7 M-N').

Taken together, these results are consistent with a role for CYP26 enzymes in mediating RA-dependent patterning processes in different regions of the developing ectoderm. Furthermore, they support previous findings suggesting an implication of RA signaling in neural specification processes in the amphioxus ectoderm (Schubert et al., 2004, Zieger, 2016).

\section{CYP26 has a major influence on the establishment of anterior-posterior identity in the developing amphioxus central nervous system}

The importance of RA signaling for patterning the developing amphioxus CNS has been well documented in the literature (Escriva et al., 2002; Holland and Holland, 1996; Schubert et al., 2006), but the roles for CYP26 in this process remain elusive. Given that our six marker genes, En, Pax2/5/8, Pitx, Pax6, TIx, and Prdm12, are expressed in different regions of the developing CNS, we next studied their expression in embryos and larvae treated with R115866 and compared the resulting patterns to those obtained in embryos and larvae treated with either RA or BMS493. The CNS expression of these genes has previously been described for En, Pax2/5/8, Pitx, Pax6, and TIx in B. floridae (Beaster-Jones et al., 2008; Boorman and Shimeld, 2002; Glardon et al., 1998; Holland et al., 1997; Holland and Holland, 1998; Kaltenbach et al., 2009; Kozmik et al., 1999), for En, Pax2/5/8, Pitx, and Prdm12 in B. lanceolatum (Somorjai et al., 2008; Thélie et al., 2015) as well as for Pitx in B. japonicum (Yasui et al., 2000). Of note, only the expression of $B$. floridae $P a x 2 / 5 / 8$ has already been analyzed in the CNS of embryos and larvae following treatments with RA or the RAR antagonist BMS009 (Schubert et al., 2006).

The expression domains of the six marker genes along the A-P axis of the developing amphioxus CNS can chiefly be subdivided into three main territories: the $\mathrm{CV}$, the $\mathrm{CNS}$ region located posterior to the CV but anterior to the primary pigment spot (PPS), and the CNS region located posterior to the PPS (Albuixech-Crespo et al., 2017; Candiani et al., 2012). In the following, we will discuss the effects of the pharmacological treatments on gene expression in each one of these three territories, in an anterior-to-posterior progression. Thus, the amphioxus $\mathrm{CV}$ is characterized by expression of Pax6, Prdm12, En, and TIx. Pax6is expressed in two domains of the $\mathrm{CV}$, an anterior one, first detectable at $24 \mathrm{hpf}$, and a posterior one, already discernable at $18 \mathrm{hpf}$ (Fig. $5 \mathrm{~A}-\mathrm{E}$ "). Expression of Prdm12 in the CV turns on even later, at $30 \mathrm{hpf}$, and is limited to a few cells close to the neuropore (Fig. 7 C-D'). En is expressed in a similar region of the $\mathrm{CV}$, but not before $36 \mathrm{hpf}$ (Fig. $2 \mathrm{E}, \mathrm{E}^{\prime}$ ). Finally, the T/x signal is detectable by $18 \mathrm{hpf}$ in a bilateral cluster of cells located at the posterior end of the CV (Fig. 6 A-D'). CYP26 inhibition affects expression of Pax6, Prdm12, and TIx in the CV. R115866 treatment hence reduces the number of Pax6-positive cells in both the anterior and posterior expression domains in the $\mathrm{CV}$, with the effect on the former being observable by $24 \mathrm{hpf}$ and that on the latter by 36 hpf (Fig. 5 F-J"). Similarly, following CYP26 inhibition, the CV-associated expression of Prdm12 is much less conspicuous at $36 \mathrm{hpf}$ (Fig. $\left.7 \mathrm{H}, \mathrm{H}^{\prime}\right)$. Of note, although expressed in the same region of the $\mathrm{CV}$, the En signal is unaffected by CYP26 inhibitor treatments (Fig. $2 \mathrm{~J}, \mathrm{~J}$ '). Contrasting the effects on Pax6 and Prdm12, T/x expression in the CV is expanded by R115866, with the appearance of supernumerary $T / x$-positive cells in the posterior $\mathrm{CV}$ at $30 \mathrm{hpf}$ (Fig. $\left.6 \mathrm{H}, \mathrm{H}^{\prime}\right)$. The effects induced by exogenous RA are generally comparable to those obtained by CYP26 inhibition. RA thus reduces the number of stained cells both in the anterior and posterior expression domains of Pax 6 in the $\mathrm{CV}$, the former by $24 \mathrm{hpf}$, which is similar to R115866, and the latter by $30 \mathrm{hpf}$, which is earlier than what is observed with $\mathrm{R} 115866$ (Fig. 5 M-N"). Likewise, Prdm12 expression in the CV at $36 \mathrm{hpf}$ is less conspicuous in embryos treated with RA (Fig. 7 L, L'), while En expression in the CV is generally unaffected (Fig. $2 \mathrm{O}, \mathrm{O}^{\prime}$ ). Finally, like R115866, exogenous RA also induces an increase in the number of $T / x$-positive cells in the CV (Fig. 6 L,L'). Contrary to the effects observed with either R115866 or RA, BMS493 treatments do not affect the CV-associated expression of Pax6 (Fig. 5 P-T'), Prdm12 (Fig. 7 O-P'), En (Fig. 2 T-T') or TIx (Fig. 6 M-P'). These results thus suggest that normal $\mathrm{CV}$ patterning does not require active RA signaling and that endogenous RA levels in this anterior-most part of the developing amphioxus CNS are kept low by the activity of CYP26 enzymes.

In the second A-P CNS territory, located posterior to the CV but anterior to the PPS, Prdm12, Pax2/5/8, En, and T/x are expressed. In this region, Prdm12 is first detectable in a few cells located just anterior to the PPS at $24 \mathrm{hpf}$ (Fig. 7 B,B'). This domain is subsequently expanded further anteriorly at 30 and $36 \mathrm{hpf}$ (Fig. 7 C-D'). Pax2/5/8 is expressed along the entire CNS, excluding the CV, from 21 to $36 \mathrm{hpf}$ (Fig. 3 A-D"), and, at least between 18 and 24 hpf, is thus significantly overlapping the CNS domain of En (Fig. 2 A-C'). Finally, T/x is detectable at $24 \mathrm{hpf}$ in a single bilateral cluster of cells located anteriorly to the PPS (Fig. 6 D,D'). In the region posterior to the CV and anterior to the PPS, CYP26 inhibition only affects the expression of Prdm12and TIx. Thus, R115866 treatment precociously induces Prdm12 expression, at 21 hpf instead of 24 $\mathrm{hpf}$ in controls, and expands the signal anteriorly to the posterior limit of the CV (Fig. 7 E,E',F,F', G, G',H,H'). Furthermore, treatments with CYP26 inhibitor completely abolish the TIx cluster located just anterior to the PPS at $30 \mathrm{hpf}$ (Fig. $\left.6 \mathrm{H}, \mathrm{H}^{\prime}\right)$. Consistent with the effects induced by R115866, exogenous RA also leads to an earlier onset of Prdm12 expression, at $21 \mathrm{hpf}$ instead of $24 \mathrm{hpf}$, as well as to an anterior expansion of the Prdm12 domain, which might be slightly less dramatic in RA-treated than R115866-treated animals at 30 and 36 hpf (Fig. 7 I,l',J,J',K,K',L,L'). RA treatments further eliminate the TIx cluster located between the CV and the PPS (Fig. 6 L,L'). Of note, a previous report described an effect of RA treatments on the expression of $B$. floridae Pax2/5/8 in the CNS (Schubert et al., 2006), which contrasts with the findings reported 
here (Fig. 3 I-L"). The use of a significantly higher final concentration of RA in this previous work $(1 \mu \mathrm{M}$ compared to $0.1 \mu \mathrm{M})$ very likely explains the different results obtained. Coming back to our study, in the territory posterior to the CV but anterior to the PPS, BMS493 treatments lead to a delayed onset of Prdm12 expression, which remains undetectable until $30 \mathrm{hpf}$ (Fig. 7 O,O'), and to a subsequent downregulation by $36 \mathrm{hpf}$ (Fig. 7 P,P'). Surprisingly, similar to the effects induced by R115866 and RA, BMS493 treatments also induce a loss of the $T / x$-positive cell cluster located anteriorly to the PPS (Fig. 6 P,P'). In this CNS territory, both the upregulation and downregulation of RA signaling hence induce the mispatterning of specific neural populations, suggesting that these cells require intermediary RA levels for their proper specification.

In the third CNS territory, located posterior to the PPS, Pax2/5/8, En, Pitx, Prdm12, and T/xare expressed. While Pax2/5/8is conspicuously expressed in this region at 21 and $24 \mathrm{hpf}$, the signal weakens at 30 and $36 \mathrm{hpf}$ (Fig. 3 A-D"). In contrast, En is only detectable in a few cells just posterior to the PPS after 24 hpf (Fig. 2 C-E'). At that stage, Pitx expression is limited to a small cluster of cells located just posterior to the En-positive cells (Fig. 4 A-A"). During subsequent development, the Pitx domain expands posteriorly, with more cells in the CNS starting to express the gene (Fig. 4 B-C"). T/x expression in this posterior CNS domain is limited to two bilateral clusters of cells, first detectable at $18 \mathrm{hpf}$ (Fig. 6 A-A'). The overall number of cells in these two T/x clusters does not increase significantly during subsequent development (Fig. 6 B-D'). Finally, Prdm12 is expressed in a few cells just posterior to the PPS at 30 hpf (Fig. $7 \mathrm{C}, \mathrm{C}^{\prime}$ ), and this domain is expanded posteriorly at $36 \mathrm{hpf}$ (Fig. 7 D,D'). Inhibition of CYP26 function does not alter the expression of Pax2/5/8 (Fig. 3 E-H'), En (Fig. 2 F-J'), Pitx (Fig. 4 D-F') or Prdm12 (Fig. 7 G-H') and thus only affects $T / x$ in the posterior CNS: the overall number of T/x-positive cells in the two clusters is increased at $36 \mathrm{hpf}$ to between seven and eight cells (Fig. $6 \mathrm{H}, \mathrm{H}^{\prime}$ ). Similar to CYP26 inhibition, exogenous RA exclusively increases the number of $T / x$-positive cells at 36 hpf (Fig. 6 L,L') and does not impact the expression of Pax2/5/8 (Fig. 3 I-L'), En (Fig. 2 K-O'), Pitx (Fig. 4 G-l') or Prdm12 (Fig. 7 K-L'). Interestingly, while the RAR antagonist also does not affect Pax2/5/8 (Fig. 3 M-P") and En (Fig. 2 P-T') expression, at 36 hpf, BMS493 treatments strongly reduce the number of cells expressing either TIX (Fig. 6 P,P') or Pitx (Fig. 4 L-L') and completely abolish expression of Prdm12 in this posterior CNS territory (Fig. 7 P,P'). These results indicate that RA signaling is required for the specification of neural cell populations in the posterior amphioxus CNS. Given the severe effects caused by downregulation of RA signaling activity and the concurrent paucity of phenotypic changes induced by its upregulation, it is likely that this posterior region of the CNS requires high RA signaling levels for proper developmental patterning.

In sum, these data suggest that neuronal populations located at different positions along the A-P axis of the developing amphioxus CNS require different levels of RA signaling activity for their specification. Furthermore, our results reveal roles for CYP26 in distinctive A-P territories of the amphioxus CNS, some of which do not express CYP26 genes (Carvalho et al., 2017). It is thus conceivable that, as in vertebrates (Hernandez et al., 2007; White et al., 2007), one of the functions of CYP26 enzymes in amphioxus is to establish a RA gradient that is required for proper regional patterning along the A-P axis of the developing CNS.

\section{Discussion}

In the present study, we used pharmacological inhibition of CYP26 function to study the influence of CYP26 enzymes on the modulation of RA signaling activity during amphioxus development. The characterization of CYP26-2 expression, a known direct target of RA signaling in amphioxus (Carvalho et al., 2017), allowed us to identify tissues where RA degradation might be essential during development. The characterization of marker gene expression following CYP26 inhibition subsequently revealed that CYP26 function is required for patterning the anterior endoderm, the general ectoderm as well as the CNS, while it might be dispensable for mesoderm development. Although the latter notion is consistent with previous studies in amphioxus suggesting that disruption of RA signaling does not affect mesodermal patterning (Bertrand et al., 2015; Schubert et al., 2005), further work is needed to unequivocally demonstrate that amphioxus mesoderm development is not regulated by RA signaling. Finally, comparisons of CYP26 inhibition with the global increase (i.e. RA treatment) or reduction (i.e. RAR antagonist treatment) of RA signaling activity yielded insights into the tissue specificity of CYP26 action in developing amphioxus embryos and larvae.

In general, CYP26 inhibition and exogenous RA induce comparable defects during amphioxus development, which is consistent with our current understanding of the feedback loops controlling endogenous RA levels (Carvalho et al., 2017). However, our experiments revealed that $R A$ treatments induce marker gene expression changes significantly earlier than CYP26 inhibition. This is the case, for example, for endodermal expression of Pax2/5/8, Pitx, and Pax6, for ectodermal expression of Pax 6 and TIx as well as for CNS expression of Pax6. These differences can at least partially be explained by the nature of the treatments, i.e. a local increase of RA levels by inhibition of CYP26-dependent degradation versus a global induction of RA signaling activity by exogenous RA treatment. Nonetheless, the developmental effects elicited by R115866 and RA are generally very similar, suggesting that in amphioxus, as in vertebrates, the CYP26-mediated creation of local RA sinks is fundamental for the establishment of global RA signaling activity in the embryo (Rydeen et al., 2015; White et al., 2007).

In vertebrates, the activity of RA synthesizing and degrading enzymes in the developing embryo have been shown to create a RA gradient that mediates RA signaling-dependent patterning along the A-P axis (Hernandez et al., 2007; Rydeen et al., 2015; Schilling et al., 2016; Shimozono et al., 2013; White et al., 2007). During amphioxus development, CYP26-2 is expressed very conspicuously in the anterior general ectoderm, CNS, endoderm, and mesoderm (Carvalho et al., 2017), while genes encoding RA production enzymes of the RALDH family are expressed in the posterior half of the embryo in endoderm and mesoderm (Sobreira et al., 2011). Hence, comparable to the situation in vertebrates, a RA gradient likely exists in developing amphioxus and functions in A-P patterning of the embryo. This morphogen gradient would be characterized by high endogenous RA concentrations in the region of RALDH activity posteriorly that decrease towards the anterior tip of the embryo and larva, with this decrease being ensured by the presence of CYP26-2. In addition, given that amphioxus CYP262 is also expressed in the posterior-most ectoderm, albeit very inconspicuously (Carvalho et al., 2017), it is further conceivable 
that a second RA gradient is set up along the posterior region of the A-P axis. This second RA gradient would then be characterized by RA concentrations that decrease from the RALDH source located in the posterior trunk region towards the CYP26 sink in the posterior-most ectoderm. Similar RA gradients have been reported along the A-P axis of vertebrate embryos, where they assume patterning functions, for example, in the developing brain (Schilling et al., 2016; Shimozono et al., 2013). Taken together, these observations suggest that RA-dependent regionalization by the differential interpretation of such morphogen gradients already patterned embryos and larvae of the last common ancestor of amphioxus and vertebrates.

Although future work, using, for example, in vivo imaging tools developed in vertebrates (Schilling et al., 2016; Shimozono et al., 2013), will be required to unequivocally demonstrate the existence of RAgradient(s) in amphioxus, it is nonetheless tempting to speculate, which tissues might be regulated by a morphogen gradient during amphioxus development. In general, they should be characterized by highly regionalized responses to RA along the A-P axis. While our results indicate functions for RA signaling and CYP26 enzymes in the developing CNS, ectoderm, and endoderm, we were unable to identify any in the mesoderm. This contrasts with the situation in vertebrates, where RA signaling and CYP26 enzymes are required for the proper development of different mesodermal derivatives, including, for example, the cardiovascular system and vertebrae (Rydeen and Waxman, 2014; Sakai et al., 2001). These regulatory differences are consistent with the hypothesis that, in the course of chordate evolution, mesoderm-specific functions for RA signaling and CYP26 evolved specifically in the lineage leading to extant vertebrates, after its split from the amphioxus lineage (Carvalho et al., 2017).

RA signaling in the amphioxus endoderm is known to define the posterior limit of the pharynx by activating the expression of Hox 1 in the foregut, hence limiting the expression of pro-pharyngeal genes to the pharyngeal endoderm (Schubert et al., 2005). However, it remains elusive, whether the Hox1-dependent regionalization of the amphioxus endoderm is the result of a graded response to RA, and the experimental evidence presented here did not yield additional information to clarify this issue. RAsignaling, and in particular CYP26 function, has further been implicated in the development of specific structures in the pharyngeal, i.e. anterior, endoderm, including the mouth and the anterior gill slits (Carvalho et al., 2017; Koop et al., 2014). Our results are coherent with these previous reports, as they show that the pharmacological inhibition of CYP26 leads to the downregulation of genes, such as Pax2/5/8, Pitx, and Pax6, which are expressed in specific pharyngeal structures, such as the mouth, the anterior gill slits, the endostyle as well as Hatschek's left and right diverticula. Consistently, CYP26-2 expression is particularly conspicuous in the anterior pharyngeal compartment that comprises these structures (Carvalho et al., 2017; Koop et al., 2014). One of them, Hatschek's left diverticulum, will give rise to Hatschek's pit, the likely amphioxus homolog of the vertebrate adenohypophysis (Kozmik et al., 2007). Adenohypophysis development in amphioxus might thus take place in a RA-free environment, which contrasts with the situation in vertebrates, where the formation of Rathke's pouch, i.e. of the adenohypophyseal placode (Patthey et al., 2014; Schlosser et al., 2014), requires RA signaling (Maden et al., 2007). It is likely that this inverse dependence on RA is correlated with the different embryonic origins of Hatschek's left diverticulum in amphioxus and the adenohypophyseal placode in vertebrates: while the former arises as a pouch from the anterior gut and is thus derived from the endoderm, the latter is formed by invagination from the stomodeal ectoderm (Patthey et al., 2014; Schlosser et al., 2014).

In the amphioxus ectoderm, previous studies have already established a role for RA signaling in patterning the general ectoderm and in controlling the distribution of ESNs along its A-P axis (Schubert et al., 2004). Even though CYP26-2 is expressed in both the anterior-most and posterior-most amphioxus ectoderm (Carvalho et al., 2017), our marker gene analyses did not yield results that are indicative of a functional RA gradient in the general ectoderm. While CYP26 function is known to be required in the posterior ectoderm for tail fin development (Carvalho et al., 2017), it also seems to be involved in the regulation of Pax 6 anteriorly. Of note, the Pax6-positive territory in the rostral ectoderm of amphioxus contains specific populations of chemosensory cells (Lacalli and Hou, 1999) and has been proposed to be homologous to the olfactory placode of vertebrates (Patthey et al., 2014; Schlosser et al., 2014). Although RA signaling has been implicated in olfactory placode development in vertebrates, for example in the production and maintenance of Pax6-positive progenitor cells (Paschaki et al., 2013), a role for CYP26 in this process still remains elusive.

Finally, our data are coherent with the existence of a graded response to RA signaling in the amphioxus CNS. Indeed, at least three domains along the A-P axis of the CNS seem to react differently to alterations of endogenous RA signaling levels: (1) the $\mathrm{CV}$, which represents the homolog of the forebrain and midbrain regions of vertebrates, (2) the region located posterior to the $\mathrm{CV}$ and anterior to the PPS that corresponds to the anterior and center of the vertebrate hindbrain, and (3) the region of the CNS located posterior to the PPS, which is the equivalent of the vertebrate posterior hindbrain and spinal cord (Albuixech-Crespo et al., 2017; Candiani et al., 2012). In the CV, which expresses CYP26-2, the upregulation of RA signaling induces the mispatterning of Pax6 and T/x expression, while no effect is induced by RA signaling inhibition, suggesting that this domain requires very low levels of RA during development. In the intermediary region of the CNS, located posterior to the CV and anterior to the PPS, treatment with either the CYP26 inhibitor, RA or the RAR antagonist affected TIx and Prdm12expression, suggesting that both abnormally high and low RA signaling levels lead to mispatterning of specific neuronal populations, which in turn is consistent with an intermediate endogenous RA signaling activity in this CNS territory. Finally, in the domain located posterior to the PPS, RAR antagonist treatments selectively abolish Pitx as well as Prdm12 expression, while both the CYP26 inhibitor and RAdo not affect these domains of Pitx and Prdm12. The specification of these two neuronal populations, Pitxor Prdm12-positive, thus requires sustained RA signaling activity, which is readily provided in this territory of the CNS located in close proximity to the main source of endogenous RA in the posterior mesoderm and endoderm (Sobreira et al., 2011).

Of note, inhibition of CYP26 function affects the expression of marker genes in the CNS not only in the anterior region characterized by conspicuous CYP26 expression, but also in both posterior territories marked by an absence of CYP26 expression (Carvalho et al., 2017). We interpret these results as strong indications for the existence, along the A-P axis, of a CYP26-dependent RA gradient that conveys positional information to the developing amphioxus 
TABLE 1

\section{SEQUENCES OF THE OLIGONUCLEOTIDES USED AS PRIMERS FOR AMPLIFICATION OF THE INDICATED GENES FROM BRANCHIOSTOMA LANCEOLATUM}

\begin{tabular}{ll} 
Gene & Forward primer \\
\hline CYP26-2 & 5'-GGACACAAAGCTGCAAAGATGCTGG-3' \\
Engrailed & 5'-GAGTGACATTTCGGATTCGTATGCGTCTTCGGT-3' \\
Pax2/5/8 & 5'-CACGGTGGAGTGAACCAGCTC-3' \\
Pitx & 5'-GTCGCAGCAGCTCCAGGAG-3' \\
Pax6 & 5'-CCCGAGGTGGTCGCCAAGATCGCG-3' \\
Tlx & 5'-ATGGTTGGCATCATGGAATCGGAG-3' \\
Prdm12 & 5'-ATAATGAAGCCGACCCTGTTTGATC-3' \\
\hline
\end{tabular}

CNS. A functional readout of this morphogen gradient could then be the activation of collinear Hox expression along the A-P axis of the amphioxus CNS, which is known to be under the control of RA signaling (Schubert et al., 2006). It is further conceivable that individual cells along the A-P gradient elicit different responses to RA depending on their cellular environments. The RA concentration gradient might hence also establish cell type specificity in the developing amphioxus embryo, a notion that has previously been proposed for both the amphioxus CNS and general ectoderm (Schubert et al., 2004; Schubert et al., 2006).

Taken together, in this study, we provide evidence for the tissuespecific action of CYP26 enzymes during amphioxus development. Furthermore, we establish that, similar to the situation in vertebrates, amphioxus CYP26 enzymes act with other components of the RA pathway to set up a RA gradient along the A-P axis that is required for patterning at least the developing CNS. The evolution of a RA morphogen gradient functioning during development to convey A-P patterning information might thus date back to the origin of chordates.

\section{Materials and Methods}

\section{Amphioxus adult husbandry, embryo rearing, and pharmacological treatments}

Sexually mature European amphioxus (B. lanceolatum) were collected by dredging in Argelès-sur-Mer, France, and retrieved from the sand by sieving. After transportation, animals were transferred into tanks, with about 10 to 15 adults per aquarium. The water temperature was kept constant at 16 to $17^{\circ} \mathrm{C}$, and the animals were maintained under a spring-like day/night period (14 hours of light and 10 hours of absolute darkness). Spawning was induced by a 36 -hour thermal shock at $23^{\circ} \mathrm{C}$, as previously described (Fuentes et al., 2004). Following in vitrofertilization, embryos were reared in artificial seawater at $19^{\circ} \mathrm{C}$ in complete darkness. Pharmacological treatments were performed at the late blastula stage (6 hpf) with the CYP26 inhibitor $\mathrm{R} 115866$ (at $0.5 \mu \mathrm{M}$ ) (provided by Janssen Research \& Development, a division of Janssen Pharmaceutica NV, Beerse, Belgium), all-trans RA (at $0.1 \mu \mathrm{M})$ (Sigma-Aldrich, Saint-Quentin Fallavier, France), and the RAR antagonists BMS493 (at $1 \mu \mathrm{M}$ ) (Sigma-Aldrich, Saint-Quentin Fallavier, France). The compounds were dissolved in dimethyl sulfoxide (DMSO) to obtain a 1000X stock solution and subsequently added to the cultures in a 1:1000 dilution to yield the respective final concentrations. As controls, cultures were treated with DMSO alone at a final dilution of 1:1000.

\section{Gene cloning, in situ hybridization and imaging}

Total RNA was extracted from B. lanceolatum embryos at different developmental stages according to established protocols (Yu and Holland, 2009), and cDNA was synthesized using the SuperScriptlll reverse transcription kit (Invitrogen, Cergy Pontoise, France). B. lanceolatum CYP26-2, En, Pax2/5/8, Pitx, Pax6, TIx, and Prdm12 were amplified by

\author{
Reverse primer \\ 5'-CCTTTTCTTTACATCGCGACATTGATGTC-3' \\ 5'-GCTAGTCATGCATGTCCAGGCTATGCTCG-3' \\ 5'-GAACAGCAACTGGATAGTGGCCG-3' \\ 5'-GAGTGTTGCTTGGCCTTCAGTC-3' \\ 5'-CTGAGCCTCCGTTAGCGTGTGACATGTGA-3' \\ 5'-TAGCAGATCGTTGGCGTGGTGAG-3' \\ 5'-GACGTTCGTTCGGTCGCCATGTTATA-3'
}

PCR using the gene-specific primers listed in Table 1 and cloned into commercially available vectors. The obtained clones were subsequently validated by sequencing on both strands. Gene accession numbers are as follows: CYP26-2 (KX118108), En(KP235487), Pax2/5/8(EU685298), Pitx (EU685299), Pax6 (MF536418), TIX (KY569298), and Prdm12(KP235486). For in situ hybridization, following the treatments, $B$. lanceolatum embryos and larvae were cultured and subsequently fixed in $4 \%$ paraformaldehyde at different developmental stages, between the late gastrula and early larva stages (i.e. between 12 and $36 \mathrm{hpf}$ ), as previously described (Yu and Holland, 2009). Antisense riboprobe synthesis and in situ hybridization experiments were subsequently performed following the established protocols (Yu and Holland, 2009). After in situ hybridization, B. lanceolatum embryos and larvae were photographed as whole mounts using Zeiss DIC (differential interference contrast) optics and an AxioCam ERc 5s camera (Carl Zeiss SAS, Marly-le-Roi, France). Adobe Photoshop CS6 was used for the calculation of maximal projections and for image processing. For each gene, all assayed stages (from 12 to $36 \mathrm{hpf}$ ) were photographed and subsequently analyzed.

\section{Acknowledgements}

The authors are indebted to Hector Escriva from the Observatoire Océanologique de Banyuls-sur-Mer in Banyuls-sur-Mer, France, for providing Branchiostoma lanceolatum adults and to Laurent Gilletta, Loann Gissat, and Sophie Collet for help with maintaining amphioxus adults at the Observatoire Océanologique de Villefranche-sur-Mer in Villefranche-surMer, France. The authors would further like to thank Janssen Research \& Development, a division of Janssen Pharmaceutica NV, for providing the CYP26 inhibitor. This study was supported by a grant from the Agence Nationale de la Recherche (ANR-11-JSV2-002-01) and by funds from the Réseau André Picard (ANR-11-IDEX-0004-02, Sorbonne Universities) to Michael Schubert. João E. Carvalho was a FCT doctoral fellow (SFRH) $B D / 86878 / 2012)$.

\section{References}

ALBALATR, CAÑESTRO C (2009). Identification of Aldh1a, Cyp26 and RAR orthologs in protostomes pushes back the retinoic acid genetic machinery in evolutionary time to the bilaterian ancestor. Chem Biol Interact 178: 188-196.

ALBUIXECH-CRESPOB, LÓPEZ-BLANCHL, BURGUERAD, MAESOI, SÁNCHEZARRONESL, MORENO-BRAVO JA, SOMORJAII, PASCUAL-ANAYAJ, PUELLES E, BOVOLENTA P, GARCIA-FERNÀNDEZ J, PUELLES L, IRIMIA M, FERRAN $\mathrm{JL}$ (2017). Molecular regionalization of the developing amphioxus neural tube challenges major partitions of the vertebrate brain. PLoS Biol 15: e2001573.

BEASTER-JONES L, KALTENBACH SL, KOOP D, YUAN S, CHASTAIN R, HOLLAND LZ (2008). Expression of somite segmentation genes in amphioxus: a clock without a wavefront? Dev Genes Evol 218: 599-611.

BERTRAND S, ALDEA D, OULION S, SUBIRANA L, DE LERA AR, SOMORJAI I, ESCRIVA H (2015). Evolution of the role of RA and FGF signals in the control of somitogenesis in chordates. PLoS One 10: e0136587.

BLOMHOFF R, BLOMHOFF HK (2006). Overview of retinoid metabolism and function. J Neurobiol 66: 606-630. 
BOORMAN CJ, SHIMELD SM (2002). Pitx homeobox genes in Ciona and amphioxus show left-right asymmetry is a conserved chordate character and define the ascidian adenohypophysis. Evol Dev 4: 354-365.

CAMPO-PAYSAA F, MARLÉTAZ F, LAUDET V, SCHUBERT M (2008). Retinoic acid signaling in development: tissue-specific functions and evolutionary origins. Genesis 46: 640-656.

CANDIANI S, MORONTI L, RAMOINO P, SCHUBERT M, PESTARINO M (2012). A neurochemical map of the developing amphioxus nervous system. BMC Neurosci 13: 59.

CARVALHO JE, SCHUBERT M (2013). Retinoic acid: metabolism, developmental functions, and evolution. In Vitamin-binding proteins: functional consequences (Eds K Dakshinamurti and S Dakshinamurti). CRC Press, Boca Raton, pp. 1-30.

CARVALHO JE, THEODOSIOU M, CHEN J, CHEVRETP, ALVAREZS, DE LERAAR, LAUDET V, CROCE JC, SCHUBERTM (2017). Lineage-specific duplication of amphioxus retinoic acid degrading enzymes (CYP26) resulted in sub-functionalization of patterning and homeostatic roles. BMC Evol Biol 17: 24.

DOBBS-MCAULIFFE B, ZHAO Q, LINNEY E (2004). Feedback mechanisms regulate retinoic acid production and degradation in the zebrafish embryo. Mech Dev 121: 339-350.

ESCRIVA H, HOLLAND ND, GRONEMEYER H, LAUDET V, HOLLAND LZ (2002). The retinoic acid signaling pathway regulates anterior/posterior patterning in the nerve cord and pharynx of amphioxus, a chordate lacking neural crest. Development 129: 2905-2916.

FUENTES M, SCHUBERT M, DALFO D, CANDIANI S, BENITO E, GARDENYES J, GODOY L, MORET F, ILLAS M, PATTEN I, et al., (2004). Preliminary observations on the spawning conditions of the European amphioxus (Branchiostoma lanceolatum) in captivity. J Exp Zoolog B 302: 384-391.

GLARDON S, HOLLAND LZ, GEHRING WJ, HOLLAND ND (1998). Isolation and developmental expression of the amphioxus Pax-6 gene (AmphiPax-6): insights into eye and photoreceptor evolution. Development 125: 2701-2710.

HERNANDEZ RE, PUTZKE AP, MYERS JP, MARGARETHA L, MOENS CB (2007). Cyp26 enzymes generate the retinoic acid response pattern necessary for hindbrain development. Development 134: 177-187.

HOLLAND LZ, HOLLAND ND (1998). Developmental gene expression in amphioxus: new insights into the evolutionary origin of vertebrate brain regions, neural crest, and rostrocaudal segmentation. Am Zool 38: 647-658.

HOLLAND LZ, HOLLAND ND (1996). Expression of AmphiHox-1 and AmphiPax-1 in amphioxus embryos treated with retinoic acid: insights into evolution and patterning of the chordate nerve cord and pharynx. Development 122: 1829-1838.

HOLLAND LZ, KENE M, WILLIAMS NA, HOLLAND ND (1997). Sequence and embryonic expression of the amphioxus engrailed gene (AmphiEn): the metameric pattern of transcription resembles that of its segment-polarity homolog in Drosophila. Development 124: 1723-1732.

KALTENBACH SL, YU J-K, HOLLAND ND (2009). The origin and migration of the earliest-developing sensory neurons in the peripheral nervous system of amphioxus. Evol Dev 11: 142-151.

KOOPD, CHENJ, THEODOSIOU M, CARVALHOJE, ALVAREZS, LERAAR de, HOLLAND LZ, SCHUBERT M (2014). Roles of retinoic acid and Tbx1/10 in pharyngeal segmentation: amphioxus and the ancestral chordate condition. EvoDevo 5: 36.

KOZMIK Z, HOLLAND ND, KALOUSOVA A, PACES J, SCHUBERT M, HOLLAND LZ (1999). Characterization of an amphioxus paired box gene, AmphiPax2/5/8: developmental expression patterns in optic support cells, nephridium, thyroid-like structures and pharyngeal gill slits, but not in the midbrain-hindbrain boundary region. Development 126: 1295-1304.

KOZMIK Z, HOLLAND ND, KRESLOVA J, OLIVERI D, SCHUBERT M, JONASOVA K, HOLLAND LZ, PESTARINO M, BENES V, CANDIANI S (2007). Pax-Six-EyaDach network during amphioxus development: conservation in vitro but context specificity in vivo. Dev Biol 306: 143-159.

LACALLI TC, HOU S (1999). A reexamination of the epithelial sensory cells of amphioxus (Branchiostoma). Acta Zool 80: 125-134.

LU T-M, LUO Y-J, YU J-K (2012). BMP and Delta/Notch signaling control the development of amphioxus epidermal sensory neurons: insights into the evolution of the peripheral sensory system. Development 139: 2020-2030.

MADEN M, BLENTIC A, REIJNTJES S, SEGUIN S, GALE E, GRAHAM A (2007). Retinoic acid is required for specification of the ventral eye field and for Rathke's pouch in the avian embryo. Int J Dev Biol 51: 191-200.

PASCHAKI M, CAMMAS L, MUTA Y, MATSUOKA Y, MAK S-S, RATAJ-BANIOWSKA M, FRAULOB V, DOLLE P, LADHER RK (2013). Retinoic acid regulates olfactory progenitor cell fate and differentiation. Neural Develop 8: 13.

PATTHEY C, SCHLOSSER G, SHIMELD SM (2014). The evolutionary history of vertebrate cranial placodes - I: Cell type evolution. Dev Biol 389: 82-97.

RYDEEN A, VOISIN N, D'ANIELLO E, RAVISANKAR P, DEVIGNES C-S, WAXMAN JS (2015). Excessive feedback of Cyp26a1 promotes cell non-autonomous loss of retinoic acid signaling. Dev Biol 405: 47-55.

RYDEEN AB, WAXMAN JS (2014). Cyp26 enzymes are required to balance the cardiac and vascular lineages within the anterior lateral plate mesoderm. Development 141: 1638-1648.

SAKAI Y, MENO C, FUJII H, NISHINO J, SHIRATORI H, SAIJOH Y, ROSSANT J, HAMADA H (2001). The retinoic acid-inactivating enzyme CYP26 is essential for establishing an uneven distribution of retinoic acid along the anterio-posterior axis within the mouse embryo. Genes Dev 15: 213-225.

SCHILLING TF, SOSNIK J, NIE Q (2016). Visualizing retinoic acid morphogen gradients. Methods Cell Biol 133: 139-163.

SCHLOSSER G, PATTHEY C, SHIMELD SM (2014). The evolutionary history of vertebrate cranial placodes II. Evolution of ectodermal patterning. Dev Biol389:98-119.

SCHUBERT M, HOLLAND ND, ESCRIVA H, HOLLAND LZ, LAUDET V (2004). Retinoic acid influences anteroposterior positioning of epidermal sensory neurons and their gene expression in a developing chordate (amphioxus). Proc Natl Acad Sci USA 101: 10320-10325.

SCHUBERT M, HOLLAND ND, LAUDET V, HOLLAND LZ (2006). A retinoic acid-Hox hierarchy controls both anterior/posterior patterning and neuronal specification in the developing central nervous system of the cephalochordate amphioxus. Dev Biol 296: 190-202.

SCHUBERT M, YU J-K, HOLLAND ND, ESCRIVA H, LAUDET V, HOLLAND LZ (2005). Retinoic acid signaling acts via Hox1 to establish the posterior limit of the pharynx in the chordate amphioxus. Development 132: 61-73.

SHIMOZONO S, IIMURA T, KITAGUCHI T, HIGASHIJIMA S, MIYAWAKI A (2013). Visualization of an endogenous retinoic acid gradient across embryonic development. Nature 496: 363-366.

SOBREIRA TJP, MARLÉTAZ F, SIMÕES-COSTA M, SCHECHTMAN D, PEREIRA AC, BRUNET F, SWEENEY S, PANI A, ARONOWICZ J, LOWE CJ, DAVIDSON B, LAUDET V, BRONNER M, OLIVEIRA PSL de, SCHUBERT M, XAVIER-NETO $J$ (2011). Structural shifts of aldehyde dehydrogenase enzymes were instrumental for the early evolution of retinoid-dependent axial patterning in metazoans. Proc Natl Acad Sci USA 108: 226-231.

SOMORJAI I, BERTRAND S, CAMASSESA, HAGUENAUERA, ESCRIVAH (2008). Evidence for stasis and not genetic piracy in developmental expression patterns of Branchiostoma lanceolatum and Branchiostoma floridae, two amphioxus species that have evolved independently over the course of 200 Myr. Dev Genes Evol 218: 703-713.

SOUKUP V, YONG LW, LU T-M, HUANG S-W, KOZMIK Z, YU J-K (2015). The Nodal signaling pathway controls left-right asymmetric development in amphioxus. EvoDevo 6: 5.

THÉLIE A, DESIDERIO S, HANOTEL J, QUIGLEY I, DRIESSCHE BV, RODARI A, BORROMEO MD, KRICHA S, LAHAYE F, CROCE J, et al., (2015). Prdm12 specifies $\mathrm{V} 1$ interneurons through cross-repressive interactions with $D b x 1$ and Nkx6 genes in Xenopus. Development 142: 3416-3428.

WHITE RJ, NIE Q, LANDERAD, SCHILLING TF (2007). Complex regulation of cyp26a1 creates a robust retinoic acid gradient in the zebrafish embryo. PLoS Biol5: e304.

WHITE RJ, SCHILLING TF (2008). How degrading: Cyp26s in hindbrain development. Dev Dyn 237: 2775-2790.

YASUI K, ZHANG S, UEMURA M, SAIGA H (2000). Left-right asymmetric expression of $B b P t x$, a Ptx-related gene, in a lancelet species and the developmental left-sidedness in deuterostomes. Development 127: 187-195.

YU J-K, HOLLAND LZ (2009). Amphioxus whole-mount in situ hybridization. Cold Spring Harb Protoc 2009: pdb.prot5286.

ZIEGER E (2016). Roles of retinoic acid signaling in regulating nervous system development in the cephalochordate amphioxus (Branchiostoma lanceolatum). Doctoral Thesis Dissertation, Université Pierre et Marie Curie, Paris, France. 


\section{Further Related Reading, published previously in the Int. J. Dev. Biol.}

From the American to the European amphioxus: towards experimental Evo-Devo at the origin of chordates

Jordi Garcia-Fernàndez, Senda Jiménez-Delgado, Juan Pascual-Anaya, Ignacio Maeso, Manuel Irimia, Carolina Minguillón, Èlia BenitoGutiérrez, Josep Gardenyes, Stéphanie Bertrand and Salvatore D’Aniello

Int. J. Dev. Biol. (2009) 53: 1359-1366

https://doi.org/10.1387/ijdb.072436jg

Evolution of CUT class homeobox genes: insights from the genome of the amphioxus, Branchiostoma floridae Naohito Takatori and Hidetoshi Saiga

Int. J. Dev. Biol. (2008) 52: 969-977

https://doi.org/10.1387/ijdb.072541nt

Peter Holland, homeobox genes and the developmental basis of animal diversity

Sebastian M. Shimeld

Int. J. Dev. Biol. (2008) 52: 3-7

https://doi.org/10.1387/ijdb.072394ss

Developmental expression of the High Mobility Group B gene in the amphioxus, Branchiostoma belcheri tsingtauense

Xiangwei Huang, Lifeng Wang and Hongwei Zhang

Int. J. Dev. Biol. (2005) 49: 49-46

http://www.intjdevbiol.com/web/paper/041915xh

Cell morphology in amphioxus nerve cord may reflect the time course of cell differentiation T C Lacalli

Int. J. Dev. Biol. (2000) 44: 903-906

http://www.intjdevbiol.com/web/paper/11206331

Embryonic development of heads, skeletons and amphioxus: Edwin S. Goodrich revisited P W Holland

Int. J. Dev. Biol. (2000) 44: 29-34

http://www.intjdevbiol.com/web/paper/10761843

Amphioxus Hox genes: insights into evolution and development

$J$ Garcia-Fernàndez and $P$ W Holland

Int. J. Dev. Biol. (1996) 40: S71-S72

http://www.intjdevbiol.com/web/paper/9087701

5 yr ISI Impact Factor $(2016)=2.421$
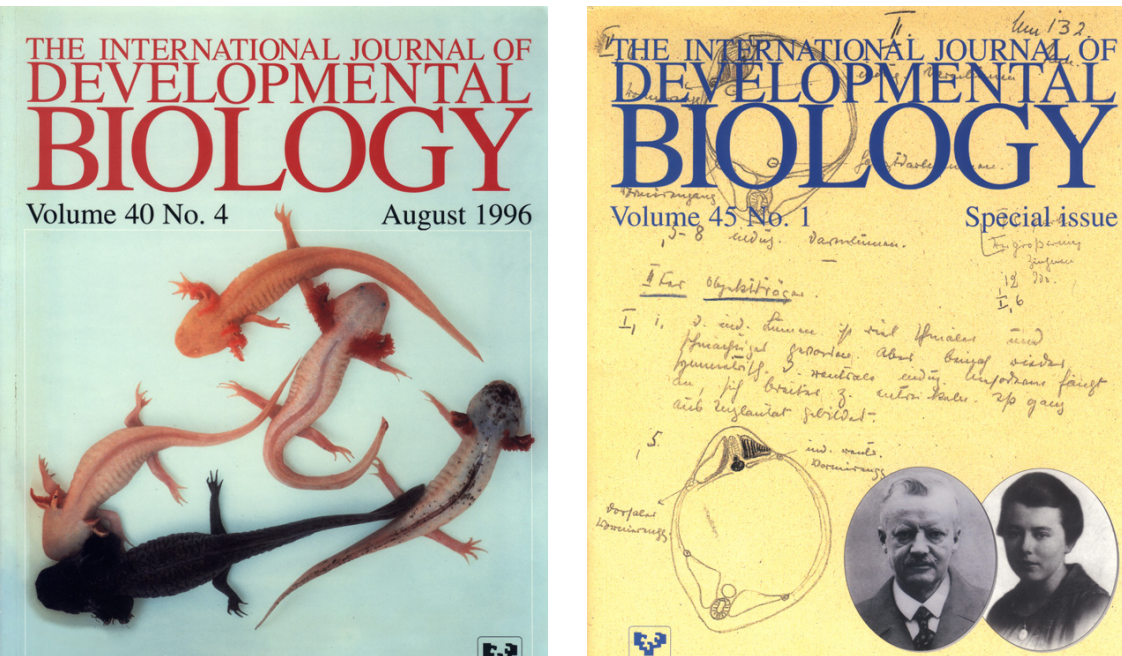

Volume 45 No. 1

Special issue
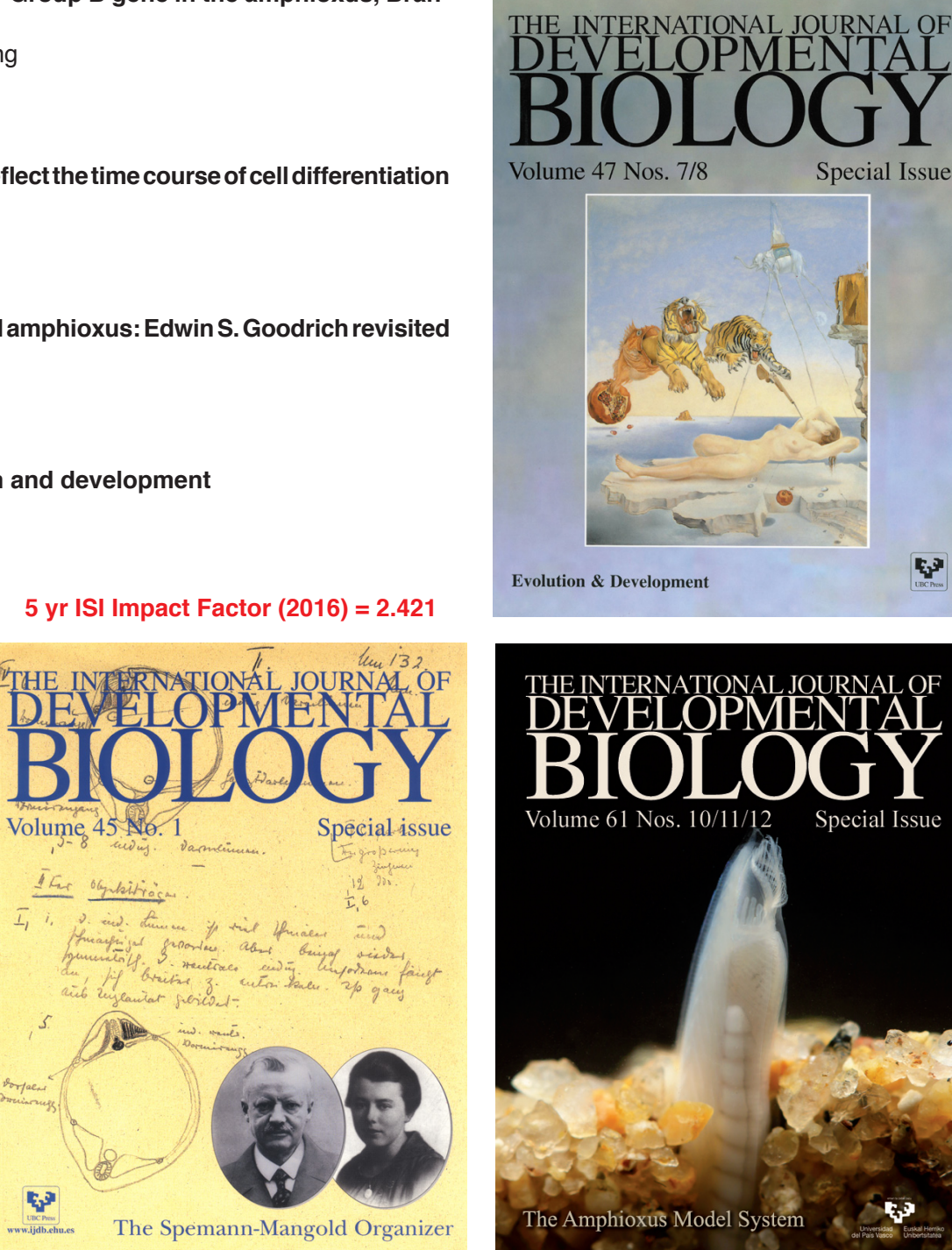

Volume 47 Nos. $7 / 8$

Special Issue

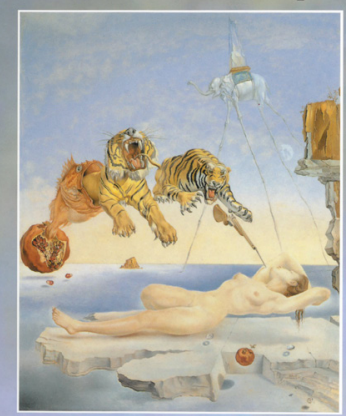

Evolution \& Developmen

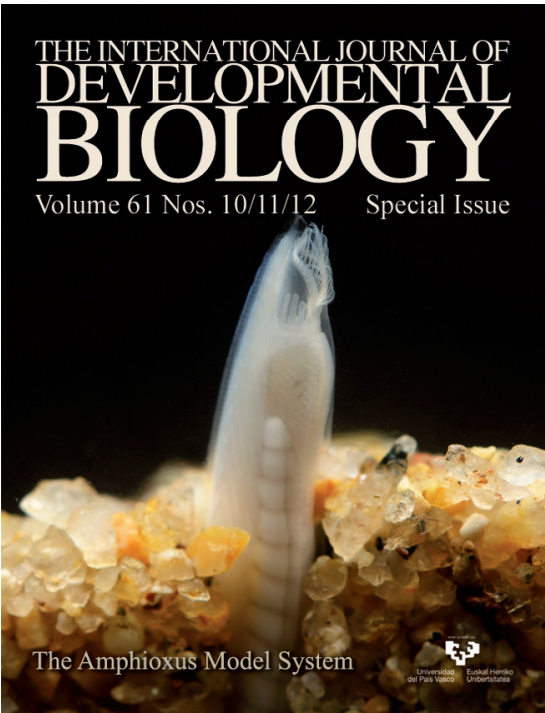

